\title{
Relação entre estado nutricional ao nascer e excesso de peso corporal em jovens
}

\author{
Elizabeth Maria Bismarck-Nasr
}

\author{
Dissertação de Mestrado apresentada ao \\ Programa de Pós-Graduação em Saúde \\ Pública para obtenção do título de Mestre. \\ Área de Concentração: Nutrição \\ Orientadora: Prof $\mathrm{Dr}^{\mathrm{a}}$ Ana Maria Dianezi \\ Gambardella
}

São Paulo

2005 
Autorizo exclusivamente para fins acadêmicos e científicos, a reprodução total ou parcial desta tese, por processos fotocopiadores. Ao usá-lo, cite a fonte. Assinatura:

Data:

$$
46736 / 2005 d x
$$


AGRADECIMENTOS 
A conclusão desta Dissertação não seria possivel sem a preciosa participação de todas as pessoas elencadas abaixo, para quem eu expresso meus sinceros agradecimentos:

Amigas e companheiras de trabalho do CREN: Mariana, Juliana, Maria Paula, Vânia, Selma, Célia, Rachel e principalmente Malú, pois permitiu que eu conciliasse meu trabalho com a carga horária exigida pelas disciplinas da pós-graduação.

Prof Dr" Ana Maria Dianezi Gambardella: por todos estes anos de orientação e amizade, que se iniciaram no primeiro ano da graduação.

Prof Dr Maria Fernanda Petroli Frutuoso: pela amizade, por todos os projetos desenvolvidos em parceria e pelas importantes colaborações na análise e discussão dos resultados.

Prof $\mathrm{Dr}^{\mathrm{a}}$ Roseli Oselka Saccardo Sarni: pela disponibilidade e atenção ao discutir e enriquecer todas as etapas do projeto, desde sua qualificação até a conclusão.

Prof Dr Wolney Conde: pela importante colaboração referente às questões metodológicas durante a qualificação do projeto e, por todas as ocasiões em que sempre se mostrou atencioso e disponivel.

Prof Kátia e Maria Tereza: por permitirem a coleta de dados nos colégios onde trabalham.

A todos os alunos que gentilmente concordaram em participar da pesquisa.

Aos meus pais, minha irmã e familiares: pelo exemplo, incentivo e paciência.

Ao meu namorado, Marcelo: pela paciência e compreensão em todas as etapas desta dissertação. 
RESUMO 
Bismarck-Nast, EM. RELAÇÃO ENTRE ESTADO NUTRICIONAL AO NASCER E EXCESSO de PESO CORPORAL EM JOVENS. São Paulo, 2005. [Dissertação de Mestrado - Faculdade de Saúde Pública da Universidade de São Paulo].

Considerando a dificuldade e o elevado custo para o tratamento da obesidade, a identificacão precoce de fatores de risco modificáveis mostra-se fundamental para sua prevenção, incluindo, entre eles, 0 inadequado crescimento intra-uterino. Objetivo: Verificar a relaçăo entre estado nutricional ao nascer e excesso de peso corporal atual em indivíduos de 14 a 23 anos de idade. Métodos: Participaram deste estudo 300 indivíduos com média de idade de 15,2 $(1,4)$ anos. Informaç̃es sobre o estado nutricional ao nascer foram coletadas no cartão da maternidade. Para a classificação do estado nutricional ao nascer utilizou-se o índice peso ao nascer por idade gestacional e o indice ponderal (IP) e, para a atual, o indice de massa corporal, a circunferência da cintura e os resultados obtidos pelo exame de bioimpedância. Resultados: $\mathbf{O}$ inadequado estado nutricional ao nascer apontou para comportamentos diferentes segundo sexo. Verificou-se diferença estatisticamente significativa entre os meninos de maior IP e prevalência de sobrepeso $(p=0,05)$ e excesso de gordura na região abdominal $(p=0,04)$; entre os meninos GIG e quantidade de massa muscular $(p=0,01)$ e, entre as meninas de maior IP e reduzido conteúdo de massa muscular $(p=0,01)$. Conclusão: Apesar do reduzido poder estatístico do estudo, pode-se sugerir que os individuos pertencentes aos extremos de peso ao nascer segundo idade gestacional e de indice ponderal, enquadram-se em uma categoria de risco para o desenvolvimento de excesso de peso corporal no futuro, sendo que esta relação mostrou-se mais evidente para o sexo masculino.

Descritores: peso ao nascer, obesidade, adolescentes 
ABSTRACT 
Bismarck-Nasr, EM. BIRTH NUTRITION STATUS AND FUTURE BODY WEIGHT EXCESS IN EARLY ADULTHOOD. São Paulo, 2005. [Master dissertation - Faculty of Public Health - University of São Paulo, Brazil].

Considering the difficulty and the excessive costs of obesity treatment, the identification of modifiable risk factors has been demonstrated to be fundamental for its prevention including the inadequate intra-utero development. Objectives: To assess the relation between fetal nutrition and future body weight excess. Methods: Three hundred individuals participated in the present study, with ages varying as $15,2 \pm 1,4$ years. Birth nutritional information was obtained from their maternity cards. Fetal status was defined by birth weight for gestational age index and ponderal index (PI). The current nutritional status has been evaluated by cut off points of BMI, waist circumference and bioelectrical impedance analysis. Results: The inadequate fetal nutrition demonstrated different behaviors according to the sex. A statistically significant difference has been verified for high PI boys and overweight prevalence $(p=0.05)$ and the abdominal fat excess $(p=0.04)$, for LGA boys and muscle mass quantity $(p=0.01)$ and, for girls with higher $P I$ and reduced muscle mass $(p=0.01)$. Conclusions: In spite of the limited statistical power of the present study, it can be suggested that individuals belonging to the extremes of birth nutritional status, are classified as a risk category for the development of corporal weight excess in the future, this relation has been demonstrated more evident for boys.

Descriptors: birth weight, obesity, adolescents 


\section{ÍNDICE}

$\begin{array}{ll}\text { 1. INTRODUÇÃO } & 01\end{array}$

$\begin{array}{ll}1.1 \text { Obesidade } & 02\end{array}$

1.2 Relação entre peso ao nascer e adiposidade $\quad 07$

1.3 Efeitos tardios do baixo peso ao nascer: Hipótese da Programação 07

1.4 Alto peso ao nascer e adiposidade futura 13

2. JUSTIFICATIVA 16

$\begin{array}{ll}\text { 3. OBJETIVOS } & 18\end{array}$

3.1 Objetivo geral 19

3.2 Objetivos específicos $\quad 19$

4. MATERIAL E MÉTODOS $\quad 20$

4.1 Delineamento, população e local de estudo 21

4.2 Coleta de dados $\quad 21$

4.3 Variáveis de estudo $\quad 22$

4.3.1 Condições de nascimento $\quad 22$

4.3.2 Diagnóstico do estado nutricional atual 23

4.3.2.1 Índice de Massa Corporal (IMC) 23

4.3.2.2 Circunferência da Cintura $\quad 24$

4.3.2.3 Quantidade de massa magra e gordura corporal 26

4.3.2.4 Baixa estatura 26

4.4 Caracterização sócio- econômica, perfil de atividade física e prática alimentar no inicio da vida $\quad 27$

4.5 Análise dos dados $\quad 27$

4.6 Questões éticas $\quad 28$

5. RESULTADOS 29

5.1 Caracterização do grupo estudado $\quad 30$

5.2 Estado nutricional ao nascer $\quad 32$

5.3 Estado nutricional atual $\quad 34$

5.4 Relação entre estado nutricional ao nascer e atual 35

5.4.1 Índice ponderal e estado nutricional atual 35

5.4.2 Estado nutricional ao nascer e atual 39 
6. DISCUSSÃO $\quad 46$

6.1 Consistência dos dados $\quad 47$

6.2 Diagnóstico do estado nutricional atual 49

6.3 Estado nutricional ao nascer e atual 53

6.3 Limitações do estudo

7. CONCLUSÕES E RECOMENDAÇÕES

8. REFERÊNCIAS BIBLIOGRÁFICAS 63

ANEXOS 


\section{ÍNDICE DE TABELAS}

Tabela 01. Distribuição dos valores médios (desvio - padrão) da idade e variáveis antropométricas ao nascer e atuais dos jovens segundo sexo.

Tabela 02: Distribuição dos jovens, segundo estado nutricional ao nascer e sexo.

Tabela 03: Distribuição dos entrevistados segundo sexo e tercis de indice ponderal.

Tabela 04: Distribuição dos entrevistados segundo tercis de índice ponderal e estado nutricional ao nascer.

Tabela 05: Distribuição dos individuos segundo sexo e idade gestacional (meses).

Tabela 06: Distribuição dos entrevistados segundo estado nutricional ao nascer e prematuridade.

Tabela 07: Distribuição dos indivíduos (número e \%) segundo sexo e diagnóstico nutricional atual.

Tabela 08: Distribuição das variáveis demográficas e antropométricas dos jovens, segundo tercis de índice ponderal.

Tabela 09: Distribuição dos jovens segundo tercis de índice ponderal e diagnóstico do estado nutricional atual.

Tabela 10: Distribuição das variáveis demográficas e antropométricas dos meninos, segundo tercis de indice ponderal.

Tabela 11: Distribuição dos meninos segundo tercis de índice ponderal e diagnóstico do estado nutricional atual.

Tabela 12: Distribuição das variáveis demográficas e antropométricas das meninas, segundo tercis de indice ponderal. 
Tabela 13: Distribuição das meninas segundo tercis de índice ponderal e diagnóstico do estado nutricional atual.

Tabela 14: Distribuição das variáveis demográficas e antropométricas dos individuos (média \pm desvio - padrão) segundo categorias de peso ao nascer.

Tabela 15: Distribuição dos indivíduos (número e \%) segundo classificação do estado nutricional ao nascer e diagnóstico nutricional atual.

Tabela 16: Distribuição das variáveis demográficas e antropométricas dos indivíduos do sexo masculino (média \pm desvio - padrão) segundo estado nutricional ao nascer.

Tabela 17: Distribuição das variáveis demográficas e antropométricas dos alunos do sexo feminino (média \pm desvio - padrão) segundo categorias de peso ao nascer.

Tabela 18: Distribuição dos meninos segundo estado nutricional ao nascer e diagnóstico nutricional atual.

Tabela 19: Distribuição das meninas segundo estado nutricional ao nascer, diagnóstico nutricional atual e menarca.

Tabela 20: Distribuição das variáveis demográficas e antropométricas dos alunos pequenos para idade gestacional (média \pm desvio - padrão) segundo prematuridade.

Tabela 21: Distribuição dos indivíduos pequenos para idade gestacional segundo diagnóstico do estado nutricional atual e prematuridade. 
1. INTRODUÇÃO 


\section{l.1Obesidade}

Considerada como fator de risco para inúmeras doenças, a obesidade caracteriza-se pelo acúmulo excessivo de gordura corporal e, atualmente, tem sido identificada como um dos mais importantes problemas de saude pública em todo o mundo devido ao aumento alarmante de sua prevalência (WHO, 2000), sendo classificada por alguns estudiosos como uma epidemia mundial (Egger \& Swinburn, 1997; Popkin \& Doak, 1998; Martorell, 2002; WHO, 2003).

De um modo geral, a obesidade comporta-se de maneira diferente conforme o nível de desenvolvimento das naçðes. Países em desenvolvimento apresentam maior proporção de indivíduos obesos nas camadas de alta renda, em mulheres de meia idade e na zona urbana, enquanto que nos países desenvolvidos, o excesso de peso corporal também atinge jovens e crianças, tanto em comunidades urbanas quanto rurais e nas camadas de baixo nível sócio - econômico (WHO, 2003).

No Brasil verificou-se comportamento semelhante aos paises em desenvolvimento durante as décadas de 70 e 80 . Entretanto, análises recentes do inquérito nutricional realizado em meados da década de 90 , nas regið̋es Nordeste e Sudeste (regiōes de maior densidade demográfica do País), apontam para um novo estágio de transição nutricional, onde algumas características referentes às naçðes mais desenvolvidas comecam a se manifestar (Monteiro et al., 2003a).

Durante as décadas de 70 e 80 observou-se rápido incremento na prevalência de obesidade na população adulta, de $5,7 \%$ para $9,6 \%$, respectivamente, independente do nível sócio econômico ou sexo, sendo que em ambos os inquéritos, as camadas de alta renda e os individuos do sexo feminino mostraram-se mais afetados por este problema (Monteiro et al., 2000a).

Dados referentes à década de 90 identificaram obesidade em cerca de $7,0 \%$ dos homens e 13,0\% das mulheres (Abrantes et al., 2003) e sinalizaram algumas 
modificaç̋es no perfil dos indivíduos com excesso de peso corporal (Monteiro et al., 2000b; Monteiro \& Conde, 2000; Monteiro et al., 2003a).

Na década passada, o aumento na prevalência de obesidade apresentou-se com maior intensidade nas camadas sociais mais pobres, na zona rural e entre os individuos do sexo masculino (Monteiro et al., 2000b; Monteiro \& Conde, 2000). Os autores ainda observaram redução na prevalência de obesidade nas mulheres pertencentes à camada de maior renda da região Sudeste.

De todas as faixas etárias que experimentaram aumento na prevalência da obesidade, atenção especial deve ser destinada à adolescência, cuja prevalência apresenta-se em intenso crescimento no mundo todo (WHO, 2000; Schneider, 2000). Estudos epidemiológicos evidenciam o excesso de peso corporal durante a adolescência como um fator preditivo para obesidade e/ ou diversas outras morbidades na vida adulta (Must et al., 1992; Clarke \& Lauer, 1993; Troiano et al., 1995; Bouchard, 1997; Dietz, 1998a e Dietz, 1998b).

$O$ índice de massa corporal tem sido utilizado internacionalmente para avaliação do estado nutricional de adolescentes. Encontram-se na literatura várias propostas que sugerem diferentes pontos de corte, considerando sexo e faixa etária, baseados principalmente na população norte -americana, tomando dificil a comparaça entre os resultados obtidos em diversos estudos (Must et al., 1991; Himes \& Dietz, 1994; Sichieri \& Allam, 1996; Cole et al., 2000).

Recentemente, Cole et al, (2000) estabeleceram pontos de corte para diagnóstico de sobrepeso e obesidade para crianças e adolescentes, segundo sexo e idade, considerando como referência uma coletânea de inquéritos nutricionais de diversos paises, resultando em uma amostra internacional. Tal proposta resultou de uma força tarefa intemacional que discutiu a questão da obesidade em crianças e adolescentes, sugerindo uma padronização para classificação do estado nutricional nestas faixas etárias. 
Com base nestes valores, verificou-se que a prevalência de sobrepeso em adolescentes brasileiros triplicou no período compreendido entre as décadas de $70 \mathrm{e}$ 90 nas regiões Nordeste e Sudeste, passando de 3,7\% para 12,6\%, enquanto a prevalência de desnutrição apresentou queda de $16,1 \%$ para $9,6 \%$, ilustrando o processo de transição nutricional no qual se encontra o País, principalmente em áreas urbanas (Wang et al., 2002). Os autores sugerem que as melhorias econômicas ocorridas no periodo permitiram modificações nos padrões de atividade fisica e alimentação, refletindo em inatividade física e excesso de consumo de alimentos com alta densidade energética, fatores que poderiam explicar a substituição do problema da desnutrição pela obesidade nesta faixa etária.

Dados referentes ao estado nutricional dos adolescentes que participaram da Pesquisa sobre Padrões de Vida (PPV), realizada no final da década de 90, nas regiões Nordeste e Sudeste, encontram-se disponiveis em diversos estudos que detectaram resultados diferentes devido às divergências quanto ao critério para classificação do IMC (Abrantes et al., 2002; Abrantes et al., 2003; Magalhães \& Mendonça, 2003).

Menor prevalência de excesso de peso corporal em adolescentes (6,6\% de sobrepeso e 4,2\% de obesidade) foi observada no Nordeste quando comparada à região Sudeste, que apresentou prevalências de $10,4 \%$ de sobrepeso e $1,7 \%$ de obesidade, sendo o sexo feminino o mais afetado pelo problema em ambas as regióes (Abrantes et al., 2002). Para classificação do estado nutricional dos adolescentes os autores consideraram os valores de IMC propostos por Must et al. (1991), segundo sexo e idade para a população norte -americana.

Achados semelhantes foram descritos por Magalhães \& Mendonça (2003), que também adotaram o mesmo critério (Must et al., 1991) para avaliação do estado nutricional de adolescentes com idades entre 15 e 20 anos, residentes nas regióes Nordeste e Sudeste. As autoras detectaram prevalência de 11,53\% de excesso de peso (sobrepeso e obesidade) na região Sudeste e $8,45 \%$, na Nordeste, principalmente na área urbana As meninas do Nordeste mostraram maior risco de sobrepeso/ obesidade quando comparadas aos meninos, ocorrendo o oposto no 
Sudeste. A maior prevalência de excesso de peso entre os adolescentes encontra-se na camada de alto nivel sócio -econômico, com exceção das meninas do Sudeste, fato que também foi descrito por Monteiro \& Conde (1999) em relação às mulheres adultas desta região.

\begin{abstract}
Abrantes et al. (2003), considerando os pontos de corte propostos por Cole et al. (2000) verificaram maior prevalência de sobrepeso $(11,3 \%)$ e obesidade $(1,9 \%)$ entre as adolescentes quando comparadas aos meninos, que mostraram valores de $8,6 \%$ para sobrepeso e 1,6\%, obesidade. Vale ressaltar que os achados referem-se aos valores médios segundo sexo para as regióes Nordeste e Sudeste, não discriminando as diferenças entre as duas regiões.
\end{abstract}

Recentemente, estabeleceram-se critérios para classificação dos aspectos relacionados à prevenção e gênese da obesidade, considerando o tipo de delineamento, critérios metodológicos e qualidade dos estudos nos quais tais evidências foram notificadas, distribuindo-as em evidências convincentes, prováveis, possiveis e insuficientes (Quadro 01). 
Quadro 01: Aspectos relacionados à promoção e prevenção do ganho de peso corporal e obesidade, segundo classificação da força da evidência observada.

\begin{tabular}{|l|l|l|}
\hline Tipo de evidencia & \multicolumn{1}{|c|}{ Aspectos protetores } & \multicolumn{1}{|c|}{ Aspectos promotores } \\
\hline Convincente & $\begin{array}{l}\text { Prática de atividade fisica regular, } \\
\text { Dietas com alto teor de fibras. }\end{array}$ & $\begin{array}{l}\text { Estilo de vida sedentário; } \\
\text { Consumo elevado de alimentos com } \\
\text { alta densidade energética e baixo } \\
\text { conteúdo de micronutrientes* }\end{array}$ \\
\hline Provável & $\begin{array}{l}\text { Ambientes escolares e domiciliares } \\
\text { que promovam escolhas alimentares } \\
\text { saudáveis para as crianças es } \\
\text { adolescentes; } \\
\text { Aleitamento materno. }\end{array}$ & $\begin{array}{l}\text { Marketing direcionado às redes de } \\
\text { Fast-Food e aos alimentos } \\
\text { industrializados de alta densidade } \\
\text { energética; } \\
\text { Consumo elevado de refrigerantes } \\
\text { líquidos açucarados; } \\
\text { Condições sócio -econômicas } \\
\text { adversas (em paises } \\
\text { desenvolvimento, principalmente para } \\
\text { as mulheres). }\end{array}$ \\
\hline Possível & $\begin{array}{l}\text { Consumo de alimentos com baixo } \\
\text { indice glicêmico. }\end{array}$ & $\begin{array}{l}\text { Tamanho exagerado das porções dos } \\
\text { alimentos disponiveis ao consumidor, } \\
\text { Alto consumo de refeições preparadas } \\
\text { fora do ambiente domiciliar, } \\
\text { Comportamentos alimentares muito } \\
\text { restritivos seguidos de episódios de } \\
\text { elevado consumo alimentar. }\end{array}$ \\
\hline Insuficiente & $\begin{array}{l}\text { Maior fracionamento da dieta. } \\
\text { Nutrição no periodo intra -uterino } \\
\text { (baixo e alto peso ao nascer). }\end{array}$ \\
\hline
\end{tabular}

Fonte: WHO (2003)

- Alimentos com alta densidade energética e baixo conteúdo de micronutrientes costumam ser industrializados e ricos em gordura e carboidratos simples. 


\subsection{Relação entre peso ao nascer e adiposidade}

Considerada como evidência insuficiente por especialistas (WHO, 2003), devido ao escasso número de estudos com delineamento adequado para atribuir causalidade, 0 impacto da nutrição no início da vida tem sido bastante investigado por uma série de pesquisadores. A relação entre peso ao nascer e adiposidade apresenta-se em forma de " $U$ ", ou seja, os extremos de peso ao nascer parecem interferir no estado nutricional futuro de indivíduos que nasceram com estas características, predispondo-os ao excesso de peso corporal (Martorell et al., 2001).

Tanto a exposiçăo intra- útero à desnutrição quanto à hiperglicemia, que acarretam em baixo e alto peso ao nascer, respectivamente, parecem afetar a organização e o desenvolvimento de alguns centros do hipotálamo, responsáveis pelo controle da ingestão alimentar (centros da fome e saciedade) e da atividade do sistema nervoso simpático (Weyer et al., 2000; Beall et al., 2004).

\subsubsection{Efeitos tardios do baixo peso ao nascer: Hipótese da Programação}

Estudos recentes sugerem que algumas doenças, como diabetes tipo 2, coronariopatias, hipertensão arterial e obesidade, relacionam-se à um inadequado crescimento intra- uterino (Lucas et al, 1999; Godfrey \& Barker, 2000, lliadou et al., 2004), fenômeno denominado, pela maioria dos autores por programaçao ou hipótese da origem fetal de doenças.

Entende-se por programação a modificação permanente na estrutura, fisiologia ou metabolismo de um órgão devido a estímulos ou agravos durante um periodo crítico de desenvolvimento (Lucas, 1994; Law, 2001). Um dos mais importantes tipos de programação consiste naquele induzido pela nutrição no início da vida, sendo o baixo peso ao nascer um marcador de deficiente nutriçăo fetal (Lucas et al., 1999).

No caso da desnutrição intra -uterina, o feto desenvolve mecanismos de adaptação metabólicos e endócrinos para sua sobrevivência em situações de restrição 
nutricional, no entanto, após o nascimento, com a normalizaçăo da oferta de alimentos, esta adaptação pode acarretar em efeitos deletérios em longo prazo, como obesidade e intolerância à glicose (Robinson, 2001; Godfrey \& Barker, 2000).

A hipótese da origem fetal de doenças parece relacionar-se ao crescimento intra uterino restrito e não apenas ao baixo peso ao nascer, desse modo, bebês prematuros com peso adequado para idade gestacional estariam protegidos de complicaçðes futuras (Godfrey \& Barker, 2000).

Os primeiros achados epidemiológicos sobre a hipótese de que restriçð̃es nutricionais durante o período gestacional acarretariam em alterações metabólicas irreversíveis no feto, surgiram a partir de estudos sobre a "fome holandesa" durante o final da Segunda Guerra Mundial (Ravelli et al, 1976), quando o Governo Alemão passou a diminuir a oferta calórica destinada aos residentes no nordeste da Holanda. No periodo entre Outubro de 1944 e Janeiro de 1945 o consumo energético destes individuos caiu de aproximadamente $1500 \mathrm{kcal}$ para $1000 \mathrm{kcal} \mathrm{e} \mathrm{de} \mathrm{Abril} \mathrm{a} \mathrm{Maio} \mathrm{de}$ 1945, esta cota representava cerca de $500 \mathrm{kcal}$, quando ocorreu a libertação da Holanda, finalizando este periodo.

A partir deste fato, diversas coortes passaram a ser estudadas, conforme periodo de crescimento intra-uterino e restrição calórica. Maior prevalência de obesidade, aos 18 anos, foi observada nos rapazes que sofreram restrições alimentares nos dois primeiros trimestres de gestação, período em que o hipotálamo começa a se organizar. Por outro lado, os jovens expostos à "fome" no último trimestre de gestação, periodo caracterizado pela multiplicação dos adipócitos e rápido incremento de gordura corporal, não apresentaram obesidade aos 18 anos, portanto, o periodo gestacional em que ocorre o agravo nutricional parece determinar a predisposição à obesidade futura (Ravelli et al, 1976).

Outra análise, também realizada com este grupo de indivíduos nascidos durante a "fome holandesa", detectou nas mulheres valores de índice de massa corporal (IMC) e circunferência da cintura significativamente maiores, aos 50 anos de idade, quando 
comparados aos dados antropométricos de mulheres que năo sofreram restriçðes nutricionais no periodo intra -uterino (Ravelli et al., 1999).

Law et al., (1992) sugerem que a tendência em acumular gordura na região abdominal seria uma resposta tardia ao déficit de crescimento no início da vida e, conseqüentemente, um marcador deste fato. Com base nesta afirmativa, os autores analisaram duas coortes de homens britânicos, observando redução na relação cintura/ quadril com a elevação do peso ao nascer e da placenta. Estes achados mostraram-se estatisticamente significativos independentemente da condição social, idade gestacional e hábito de fumar ou consumir álcool.

Resultados de uma coorte finlandesa verificaram maior incidência de morbi mortalidade devido a doenças cardiovasculares na idade adulta entre mulheres que apresentaram comprometimento linear (Forsén et al., 1999) e homens magros com baixo índice ponderal (Eriksson et al., 1999). Os autores apontaram para diferenças entre os sexos quanto ao tipo de desnutrição ao nascer, sendo que o risco cardiovascular nas mulheres aumentou em 10,2\% para cada centímetro a menos no comprimento ao nascer (Forsén et al., 1999) e para os homens, aumentou em 14\% para cada unidade a menos no índice ponderal (Eriksson et al., 1999).

Outro achado interessante, os homens que morreram por doencas cardíacas apresentaram valores de índice de massa corporal acima da média do grupo estudado durante o periodo dos 07 aos 15 anos de idade, sendo que aos 11 anos, os meninos apresentaram risco aumentado em $22 \%$ para cada unidade a mais de IMC. Vale ressaltar que os meninos com alto indice ponderal ao nascer mostraram risco diminuído para doenças cardiovasculares, mesmo quando obesos durante a adolescência (Eriksson et al., 1999).

Explorando um pouco mais os resultados desta coorte finlandesa, este grupo de pesquisadores detectou que a intensidade da velocidade de recuperação nutricional durante a infância e início da puberdade, principalmente referente ao ganho de peso, consistiu um importante precursor de diabetes tipo 2 , hipertensăo arterial e doenças 
cardiovasculares no futuro destes indivíduos, sendo que o risco para estas doenças mostrou-se elevado conforme aumento dos valores de IMC aos 11 anos de idade (Barker et al., 2002).

O intenso crescimento compensatório em crianças britânicas com baixo peso ao nascer relacionou-se ao risco de apresentar obesidade na idade adulta, principalmente entre os individuos do sexo masculino que alcançaram grande proporção de sua estatura final aos 07 anos de idade (Parsons et al., 2001).

Barker et al. (1997) verificaram associação positiva entre baixo peso ao nascer e IMC em adolescentes britânicas com idade entre 14 e 16 anos, independentemente do nível sócio econômico ou idade gestacional. Os autores observaram ainda tendência em acumular gordura corporal na região abdominal nas meninas com menor peso de nascimento, por meio da medida da prega cutânea subescapular e relação entre as pregas cutâneas subescapular e triciptal. No entanto, não encontraram associação com a relação cintura/ quadril, fato que os autores justificaram devido aos diferentes estágios de maturação sexual apresentados pelas adolescentes, refletindo em modificaç̃es no acúmulo de tecido adiposo.

Resultados de uma coorte na Jamaica não mostraram relação com IMC, mas com maior acúmulo de gordura na regiāo referente ao tronco corporal, obtida pela razão entre as pregas cutâneas subescapular e triciptal, aos 11 anos de idade entre dqueles que apresentaram baixa estatura na infância, sendo esta associação parcialmente explicada pelo baixo peso ao nascer (Walker et al., 2002).

Estudo comparativo entre crianças com diagnóstico de baixa estatura e eutróficas, com idade entre 08 e 11 anos, residentes em favelas no Município de São Paulo, verificou alteraç̃es metabólicas quanto à redução na oxidação lipídica no período pós-prandial, nas crianças com baixa estatura, aspecto que poderia favorecer acúmulo de gordura corporal neste grupo, mostrando consistência à teoria de que a desnutrição no início da vida acarretaria em modificações metabólicas permanentes (Hoffman et al., 2000). 
Após 36 meses, este mesmo grupo de individuos recebeu reavaliação do estado nutricional e os resultados obtidos confirmaram os achados do estudo anterior. Os adolescentes do sexo masculino (idade entre 11 e 15 anos) com baixa estatura apresentaram incremento maior na porcentagem de gordura corporal e menor na quantidade relativa de massa magra quando comparados aos adolescentes eutróficos, tais achados foram medidos por meio de dupla emissão de feixes de raios-X (DEXA) (Martins, 2003).

Resultados de uma coorte de adolescentes africanas residentes na zona rural do Senegal, com diagnóstico de baixa estatura aos 6-18 meses de vida, identificaram maior acúmulo de gordura subcutânea na região abdominal e nos braços, medidas obtidas por meio de pregas cutâneas, quando comparadas às meninas que não apresentaram comprometimento linear no início da vida (Bénéfice et al., 2001).

Os achados descritos acima, com adolescentes brasileiros, jamaicanos e senegalenses, mostram-se consistentes com a proposta sugerida por Frisancho (2003). Segundo este autor, individuos expostos à desnutrição intra-útero e durante os primeiros anos de vida, apresentam redução no metabolismo oxidativo de lipídios, utilizando carboidratos como fonte preferencial para obtenção de energia, resultando em maior depósito de gordura corporal, contribuindo para o aumento na prevalência de obesidade nas nações em desenvolvimento.

Por outro lado, alguns estudiosos referem que os efeitos tardios do baixo peso ao nascer derivam-se de um reduzido conteúdo de massa muscular, acarretando em baixa atividade metabólica (Adair, 2002; Ben-Shlomo \& Kuh, 2002; Singhal et al., 2003a) que, associada ao tipo de alimentação hipercalórica, típica da adolescência, favoreceria o acúmulo de gordura corporal, e isto explicaria o fato destes indivíduos apresentarem obesidade na idade adulta (Singhal et al., 2003a).

Algumas hipóteses plausiveis que justificariam a associação entre desnutrição intra uterina e redução na proporção de massa magra no futuro foram levantadas, tais 
como, favorecimento para o desenvolvimento de órgãos vitais, como o cérebro, em detrimento ao crescimento muscular em situaçð̃es de estresse nutricional durante 0 período gestacional; hipoglicemia fetal decorrente de fornecimento insuficiente de glicose, acarretando em reduzida secreção de insulina, que conseqüentemente, estimularia o catabolismo protéico; a má nutrição fetal reduziria a concentração do fator de crescimento insulino -dependente (IGF-1), comprometendo o crescimento da massa muscular (Singhal et al., 2003a).

Como o músculo consiste num importante local para captação de glicose devido à ação da insulina, a programação de uma reduzida proporção de massa magra, poderia acarretar em resistência à insulina, representando um dos possíveis mecanismos que relacionam o baixo peso ao nascer com risco elevado para doenças cardiovasculares no futuro (Adair, 2002; Singhal et al., 2003a).

De fato, resultados de uma coorte de crianças norte -americanas (NHANES III, 1988-1994), acompanhadas dos 02 aos 47 meses de idade, mostraram menor conteúdo de massa muscular entre àquelas que nasceram com baixo peso, independentemente da idade gestacional (Hediger et al, 1998).

Deve-se considerar a possibilidade de que a desnutrição intra -uterina acarretaria em efeitos adversos à saúde em longo prazo, uma vez que o baixo peso a nascer ainda apresenta-se como importante problema de saúde pública em paises em desenvolvimento, e que grande porção destas naçð̃es experimentam o processo denominado transição nutricional, onde mudanças econômicas, nutricionais e de estilo de vida, sobretudo referentes ao sedentarismo, permitem rápido crescimento pós-natal, predispondo estes indivíduos ao desenvolvimento da sindrome plurimetabólica (Law, 2001; Robinson, 2001; Adair, 2002; Popkin, 2002).

Sabe-se que a obesidade consiste em um importante modulador para a síndrome plurimetabólica, caracterizada por um conjunto de fatores de risco para doenças cardiovasculares, associadas à resistência à insulina, como hipertensão arterial, hipertrigliceridemia, baixa concentração de níveis séricos de lipoproteina de alta 
densidade (HDL), metabolismo anormal da glicose e hiperinsulinemia (Vanhala et al., 1998).

\subsubsection{Alto peso ao nascer e adiposidade futura}

As evidências que relacionam o alto peso ao nascer, particularmente os valores superiores a $4.000 \mathrm{~g}$, com risco elevado para o desenvolvimento de obesidade na idade adulta mostram-se satisfatoriamente consistentes em paises desenvolvidos, que atribuiram tais achados a aspectos genéticos, obesidade materna pré-gestacional, ganho de peso materno excessivo durante a gestação, diabetes gestacional e modificações metabólicas decorrentes de agravos durante o período gestacional (Dietz, 1994; Dietz, 1997; Whitaker \& Dietz, 1998; Frisancho, 2000; Martorell et al., 2001; Beall et al., 2004).

A exposição intra-útero a elevados níveis de glicose, decorrentes de diabetes gestacional ou ganho excessivo de peso materno durante a gestação, associou-se à gênese de obesidade futura, mostrando consistência com a hipótese de que, intercorrências durante 0 período gestacional, programam o organismo para modificaç⿰丿s permanentes em seu funcionamento (Whitaker \& Dietz, 1998; Beall et al., 2004).

Revisão bibliográfica realizada por Beall et al. (2004) identificou estudos experimentais conduzidos em ratos que demonstraram maior prevalência de obesidade naqueles animais em que as mães apresentaram ganho excessivo de peso durante a gestação. $O$ mecanismo físiológico envolvido nestes achados envolvia os centros do hipotálamo responsáveis pelo controle do apetite que mostraram resposta diferente ao neuropeptideo Y (NPY), que apresenta característica orexígena e, ao hormônio melanócito estimulante ( $\alpha$ - MSH), de efeito anorexígeno. Sugerindo que a exposição a altos níveis de leptina e insulina durante o período intra-uterino poderia reduzir o número de receptores destes peptídeos no hipotálamo, acarretando em resistência à leptina. 
Resultados de uma coorte norte-americana indicaram que bebês grandes para idade gestacional tornaram-se adolescentes obesos apenas quando a obesidade estava presente em pelo menos um dos pais, sugerindo que o excesso de peso corporal durante a adolescência refere-se a aspectos genéticos e não ao crescimento pré-natal (Frisancho, 2000).

Estudos realizados com gêmeos apresentam-se como ferramentas interessantes para a distinção entre fatores genéticos e ambientais na composição corporal futura, especialmente àqueles realizados com gêmeos monozigóticos, geneticamente idênticos (Loos et al., 2002; Iliadou et al, 2004).

Coorte realizada com gêmeas monozigóticas nascidas na Bélgica verificou que o peso ao nascer mostrou-se responsável por algumas das diferenças na composição corporal adulta destas mulheres, detectando entre as gemelares de maior peso ao nascer, valores superiores de estatura e peso na idade adulta (Loos et al., 2002). Os autores ainda observaram neste grupo maior proporção de massa magra e menores valores de gordura subcutânea e abdominal ao nascer.

Outro estudo longitudinal, realizado com gêmeos finlandeses (mono e dizigóticos), (Pietilăinen et al., 2001; Pietiläinen et al., 2002) verificou resultados semelhantes. Os gêmeos com alto peso e índice ponderal ao nascer apresentaram valores superiores de peso e estatura no final da adolescência, quando comparados aos indivíduos que nasceram com menores índices antropométricos, sendo que este fato foi encontrado também entre os gêmeos monozigóticos, mostrando consistência com a hipótese de que o ambiente fetal acarreta em efeitos tardios na composição corporal. Vale ressaltar que, assim como nos achados de Frisancho (2000), este grupo de pesquisadores também identificou o excesso de peso corporal nos pais como um aspecto relacionado ao sobrepeso aos 16 anos (Pietiläinen et al., 2001).

Weyer et al. (2000), analisando um grupo de indivíduos pertencentes à tribo dos Índios Pima nos Estados Unidos, que apresentam bagagem genética semelhante $e$ as prevalências de obesidade e diabetes tipo 2 mostram-se como uma das mais altas em 
todo o mundo, verificaram que os valores elevados de IMC na idade adulta encontrados nos índios com alto peso a nascer, cujas mães não desenvolveram diabetes gestacional, relacionaram-se a maiores valores de estatura e massa muscular e não de tecido adiposo.

Por outro lado, Seidman et al. (1991) estudando uma coorte de jovens Israelenses, detectaram maiores valores de IMC aos 17 anos naqueles jovens que nasceram com peso superior a $3500 \mathrm{~g}$, sendo que o risco para o desenvolvimento de sobrepeso e obesidade aumentou segundo peso ao nascer.

Resultados semelhantes foram apontados por Frutuoso (2003). Esta autora analisou os fatores associados ao sobrepeso e obesidade em uma coorte de adolescentes paulistanos, verificando que aspectos como obesidade materna e peso ao nascer superior a $3500 \mathrm{~g}$ apresentaram-se como fator de risco para excesso de peso corporal em ambos os sexos.

Monteiro et al. (2003b) analisando os resultados de uma coorte de adolescentes residentes na Região Sul do Brasil, encontraram que o peso ao nascer $(\geq 4000 \mathrm{~g})$ e o estado nutricional aos 20 e 43 meses associaram-se positiva e linearmente com sobrepeso e obesidade durante a adolescência. Os autores ainda observaram que a velocidade de crescimento elevada durante os primeiros anos de vida mostrou relação com maiores prevalências de obesidade e sobrepeso durante a adolescência, sendo estas associaçðes mais intensas para os meninos.

Vários são os achados que relacionam o ambiente gestacional com efeitos tardios na composição corporal dos individuos, evidenciando a fase gestacional como um período crítico para a gênese da obesidade. $\mathbf{O}$ modo no qual a memória metabólica incorporada durante a exposição intra-útero acarreta em prejuizos na saúde destes individuos, representa um desafio fascinante para o meio cientifico (Dietz, 1997). 
2. JUSTIFICATIVA 
Considerando-se a dificuldade e o elevado custo para o tratamento da obesidade, sua prevenção mostra-se fundamental, por este motivo, a identificação precoce de fatores de risco evitáveis, como o inadequado crescimento intra-uterino apresenta-se como um novo campo para investigação científica.

Tendo em vista as repercussões em longo prazo do inadequado crescimento intrauterino, caracterizado pelos extremos de peso ao nascer, na gênese da obesidade, e a sua alarmante incidência, em especial durante a adolescência, esta dissertação tem como objetivo verificar a associação entre peso ao nascer e excesso de peso corporal em adolescentes e jovens adultos. 
3. OBJETIVOS 


\subsection{Objetiwo Geral}

Verificar a relação entre o excesso de peso corporal em indivíduos de 14 a 23 anos de idade e estado nutricional ao nascer.

\subsection{Objetivos especificos}

Descrever as variáveis antropométricas atuais (peso, estatura, circunferência da cintura, IMC, quantidade de gordura corporal e de massa muscular) segundo sexo e estado nutricional ao nascer.

Comparar as prevalências de sobrepeso, obesidade, acúmulo excessivo de gordura abdominal, quantidade de gordura corporal acima do adequado e quantidade de massa muscular abaixo do adequado em indivíduos de 14 a 23 anos de idade, segundo sexo e estado nutricional ao nascer. 
4. MATERLAL E MÉTODOS 


\subsection{Delineamento, populaçao e local do estudo}

Realizou-se estudo do tipo transversal com indivíduos matriculados no Ensino Médio de duas escolas da rede pública do Município de São José dos Campos - SP, localizadas nas regiões Sul e Central (Figura 01).

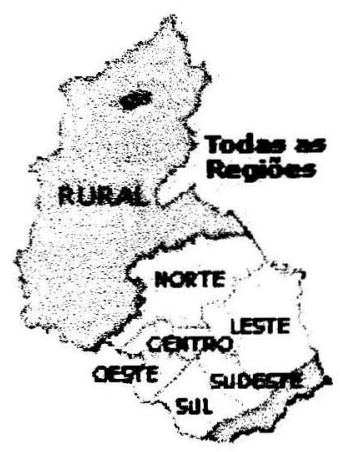

Figura 01: Representação gráfica do Município de São José dos Campos segundo regiões geográficas.

O Município de São José dos Campos localiza-se no interior do Estado de São Paulo, na região do Vale do Paraíba, distanciando-se $91 \mathrm{~km}$ da capital do Estado. No ano de 2000, classificou-se na décima primeira posição entre os Municípios do Estado segundo Índice de Desenvolvimento Humano (Fundaça SEADE, 2005). Atualmente possui 589 mil habitantes, 10\% destes com idades entre 15 e 19 anos (Secretaria Municipal de Saúde, 2004).

\subsection{Coleta de dados}

A coleta de dados foi realizada pela autora da dissertação, que recebeu treinamento sobre as técnicas para mensuração antropométrica. Os dados obtidos foram registrados em formulários próprios (Anexo I).

Após avaliação do estado nutricional, cada aluno recebeu uma carta com informaçðes referentes ao resultado de sua avaliação fisica, juntamente com folhetos 
sobre alimentaçăo saudável e orientaçoes nutricionais para manutençð̃o, ganho e perda de peso corporal, conforme diagnóstico do estado nutricional (Anexo II).

\subsection{Variáveis de estudo}

\subsubsection{Condiçes de nascimento}

Os dados referentes às condiçð̃es de nascimento dos entrevistados (idade gestacional, peso e comprimento ao nascer) foram obtidos pelo cartão de nascimento, que normalmente é oferecido pela maternidade aos pais, sobre as condiçðes de saúde do recém-nascido.

A participação na pesquisa estava condicionada à apresentação do cartão sobre as condiç̋̃es de nascimento e autorizaçăo dos pais, se fosse menor. Esse procedimento limitou a participação, uma vez que muitos dos alunos não possuíam este documento ou apresentaram cartðes com dados incompletos.

Para classificação do estado nutricional ao nascer utilizou-se o índice peso ao nascer por idade gestacional (PN/IG), que considera a relação entre o peso de nascimento e o peso correspondente ao percentil 50 da curva de crescimento intra-uterino da respectiva idade gestacional e sexo. Resultados menores de 0,85 caracterizam bebês pequenos para idade gestacional (PIG), valores superiores a 1,15 indicam bebês grandes para idade gestacional (GIG) e valores intermediários correspondem a recém nascidos adequados para idade gestacional (AIG) (Kramer et al., 1990).

Os valores correspondentes ao percentil 50 da curva de crescimento intra-uterino de Williams et al. (1984) foram utilizados como referência para o cálculo do índice peso ao nascer/ percentil 50 do peso segundo idade gestacional e sexo. Tal padrão de referência é recomendado pela Organização Mundial da Saúde (WHO, 1995).

A idade gestacional foi classificada segundo pontos de corte adotados pela Organizaçå Mundial da Saúde (WHO, 1995), que considera prematuridade, os 
valores inferiores a 37 semanas gestacionais e pós- termo os individuos nascidos com idade gestacional superior a 42 semanas.

Para avaliaç̃o da proporcionalidade ao nascer considerou-se o Índice Ponderal de Rohrer, obtido por meio da relação entre o peso ao nascer (g) e o comprimento ao nascer $(\mathrm{cm})^{3}$, multiplicando-se tal resultado por 100 (Fletcher, 1994).

O peso ao nascer foi classificado segundo critério estabelecido pela Organizaça Mundial da Saude, considerando-se baixo peso ao nascer os valores inferiores a $2500 \mathrm{~g}$ (Kramer, 1987) e alto peso ao nascer, valores superiores a $4000 \mathrm{~g}$.

\subsubsection{Diagnóstico do estado nutricional atual}

\subsubsection{1 Índice de Massa Corporal (IMC)}

Para a mensuração do peso corporal utilizou-se balança eletrônica do tipo plataforma com capacidade para $150 \mathrm{~kg}$ e graduação em $100 \mathrm{~g}$ e para a obtenção da estatura foi utilizado antropômetro, com escala em milímetros. As medidas de estatura foram realizadas em duplicata, considerando-se a média destes valores, conforme proposto por Gordon et al. (1988).

Calculou-se o valor do índice de massa corporal $\left(\mathrm{IMC}=\right.$ peso/estatura ${ }^{2}$, adotando-se como critério para diagnóstico de sobrepeso e obesidade, os pontos de corte propostos por Cole et al. (2000), segundo sexo e idade, apresentados no Quadro 02.

Tais pontos de corte foram obtidos com base em estudos transversais, de representação populacional, realizados no Brasil, Inglaterra, Estados Unidos, Holanda, Singapura e Hong Kong. Para determinaça desses pontos segundo sexo e idade, foram considerados os valores de IMC iguais a 25 para diagnóstico de sobrepeso e 30 para diagnóstico de obesidade aos 18 anos de idade, em seguida tais pontos de corte foram extrapolados para as demais idades (Cole et al., 2000). Desta forma, a determinação dos pontos de corte diferiu de outros padrões estabelecidos com base em distribuições percentilares de uma única população de referência. 
Para classificação do IMC dos indivíduos maiores de 18 anos considerou-se como ponto de corte os valores propostos pela Organização Mundial da Saúde (WHO, 2000) para diagnóstico de sobrepeso e obesidade na população adulta, ou seja, IMC $\geq 25$ para sobrepeso e IMC $\geq 30$ para obesidade.

Na descrição dos resultados, o diagnóstico de sobrepeso contemplou tanto indivíduos com sobrepeso, quanto indivíduos com obesidade.

Quadro 02: Pontos de corte de IMC para diagnóstico de sobrepeso e obesidade segundo sexo e idade.

\begin{tabular}{|c|c|c|c|c|}
\hline \multirow[t]{2}{*}{ Idade (anos) } & \multicolumn{2}{|c|}{ Sobrepeso } & \multicolumn{2}{|c|}{$\begin{array}{l}\text { Obesidade } \\
\end{array}$} \\
\hline & Meninos & Meninas & Meninos & Meninas \\
\hline 10,0 & 19,84 & 19,86 & 24,00 & 24,11 \\
\hline 10,5 & 20,20 & 20,29 & 24,54 & 24,77 \\
\hline 11,0 & 20,55 & 20,74 & 25,10 & 25,42 \\
\hline 11,5 & 20,89 & 21,20 & 25,58 & 26,05 \\
\hline 12,0 & 21,22 & 21,68 & 26,02 & 26,67 \\
\hline 12,5 & 21,56 & 22,14 & 26,43 & 27,24 \\
\hline 13,0 & 21,91 & 22,58 & 26,84 & 27,76 \\
\hline 13,5 & 22,27 & 22,98 & 27,25 & 28,20 \\
\hline 14,0 & 22,62 & 23,34 & 27,63 & 28,57 \\
\hline 14,5 & 22,96 & 23,66 & 27,98 & 28,87 \\
\hline 15,0 & 23,29 & 23,94 & 28,30 & 29,11 \\
\hline 15,5 & 23,60 & 24,17 & 28,60 & 29,29 \\
\hline 16,0 & 23,90 & 24,37 & 28,88 & 29,43 \\
\hline 16,5 & 24,19 & 24,54 & 29,14 & 29,56 \\
\hline 17,0 & 24,46 & 24,70 & 29,41 & 29,69 \\
\hline 17,5 & 24,73 & 24,85 & 29,70 & 29,84 \\
\hline 18,0 & 25,00 & 25,00 & 30,00 & 30,00 \\
\hline
\end{tabular}

\subsubsection{Circunferência da Cintura}

Para identificação de excesso de gordura corporal na região abdominal foi tomada a circunferência da cintura, uma vez que esta medida mostrou boa correlação com a distribuição de gordura corporal em adolescentes quando comparada ao exame de dupla emissão de feixes de raios X (DEXA), considerado padrão de referência para este diagnóstico (Daniels et al., 2000; Taylor et al., 2000).

Para sua obtenção utilizou-se fita métrica flexível, com escala em milímetros e disposta de modo a formar um plano paralelo ao chão e perpendicular ao corpo. As 
medidas foram realizadas com os adolescentes vestindo roupas leves, com os pés unidos e os braços estendidos ao longo do corpo, ao final da expiraçă, considerando-se o ponto médio entre a crista iliaca e a última costela As medidas foram tomadas duas vezes, utilizando-se a média destes valores (Lohman et al., 1988).

Para classificação do excesso de gordura na região abdominal nos individuos de 14 a 16 anos foram considerados os valores propostos por McCarthy et al. (2001) para adolescentes britânicos, que propuseram uma curva para a distribuição da circunferência da cintura segundo sexo e faixa etária, utilizando a mesma técnica descrita acima para aferição da circunferência da cintura Tais pontos de corte encontram-se descritos no Quadro 03.

Considerou-se o Percentil 90 como ponto de corte para identificação dos individuos menores de 17 anos com acúmulo excessivo de gordura na região abdominal, uma vez que este valor associou-se com risco elevado para dislipidemias e hiperinsulinemia em adolescentes norte- americanos (Freedman et al., 1999).

Para identificação de excesso de gordura abdominal nos indivíduos maiores de 17 anos, foram considerados como pontos de corte os valores de circunferência da cintura $\geq 88 \mathrm{~cm}$ para as mulheres $\mathrm{e} \geq 102 \mathrm{~cm}$ para os homens (WHO, 2000).

Quadro 03: Pontos de corte para circunferência da cintura segundo sexo e faixa etária.

\begin{tabular}{|lcccc|}
\hline \multirow{2}{*}{ Idade (anos) } & \multicolumn{2}{c|}{ Percentil 50 } & \multicolumn{2}{c|}{ Percentil 90 } \\
\cline { 2 - 5 } & Meninos & Meninas & Meninos & Meninas \\
\hline $10,0 \mid-$ & 58,20 & 56,70 & 65,60 & 63,61 \\
$11,0 \mid-$ & 60,20 & 58,20 & 67,90 & 65,40 \\
$12,0 \mid-$ & 62,30 & 60,00 & 70,40 & 67,30 \\
$13,0 \mid-$ & 64,60 & 61,70 & 73,10 & 69,10 \\
$14,0 \mid-$ & 67,00 & 63,20 & 76,10 & 70,60 \\
$15,0 \mid-$ & 69,30 & 64,40 & 79,00 & 71,70 \\
$16,0 \mid-$ & 71,60 & 65,30 & 81,80 & 72,60 \\
\hline
\end{tabular}

fonte: McCarthy et al. (2001). 


\subsubsection{Quantidade de massa magra e gordura corporal}

Para a determinação dos valores absolutos e relativos de massa magra e gordura corporal utilizou-se o aparelho de impedância bioelétrica RJL Systems ${ }^{\text {adotando-se }}$ os critérios propostos pelo fabricante, segundo manual de instruções (RJL Systems 2000).

A técnica da impedância bioelétrica (BIA) consiste na emissão de uma fraca corrente elétrica ( $50 \mathrm{kHz})$ e mensuração da impedância corporal, definida como a oposição de um condutor à passagem de uma corrente, sendo que no corpo humano, a quantidade de eletricidade conduzida é proporcional ao total de íons contidos no meio condutor (Lukaski, 1987).

A partir do valor obtido pela impedância, pode-se determinar a quantidade de água corporal. A quantidade de massa magra é calculada por meio de equaçðes preditivas e o total de gordura corporal, é, posteriormente, obtido pela diferença entre o peso do individuo e a quantidade de massa magra calculada (Foster \& Lukaski, 1996; Houtkooper et al., 1996).

Para identificação dos indivíduos com quantidade de gordura corporal acima do adequado e com quantidade de massa muscular abaixo do adequado considerou-se o resultado da relação entre os valores apresentados pelo indivíduo e os valores indicados como ideais pelo fabricante, multiplicando-se tal achado por 100 .

Valores de quantidade de gordura corporal superiores a $120 \%$ de adequação sinalizaram quantidade de gordura corporal acima do adequado, enquanto que valores de quantidade de massa muscular inferiores a $80 \%$ de adequação corresponderam à categoria de quantidade de massa muscular abaixo do adequado.

\subsubsection{Baixa estatura}

Para classificação de baixa estatura foram considerados os valores iguais ou inferiores a $-1,5$ escore $Z$ do índice estatura/idade (E/I), tomando-se como referência a população norte-americana (Kuczmarski et al. 2000). 
4.4 Caracterização sócio-econômica, perfil de atividade fisica e prática alimentar no início da vida

Informaçð̃es referentes à escolaridade e ocupação dos pais (ANEXO I) foram coletadas para classificação do nivel sócio econômico, adotando-se como critério para determinação de alto nivel sócio econômico, o fato dos responsáveis contemplarem, pelo menos, a categoria referente ao curso superior incompleto.

Os indivíduos responderam questionário (ANEXO I) referente à prática de atividades passivas de lazer (assistir televisão, utilizar computador e jogos eletrônicos) e exercícios físicos durante as aulas de educação física e fora do ambiente escolar, com objetivo de descrever o perfil de atividade fisica dos entrevistados.

A ocorrência da menarca foi questionada para as meninas (ANEXO I), com objetivo de identificar diferenças entre os estágios de maturação sexual, classificando como pós- púberes àquelas que já vivenciaram a menarca (WHO, 1995).

Questionário enviado aos pais, juntamente com o termo de consentimento (ANEXO III), permitiu coletar informaçðes referentes à prática alimentar no início da vida dos entrevistados. Devido ao tempo compreendido entre a data de nascimento e idade atual dos indivíduos, considerou-se somente o dado referente à oferta ou não de leite humano para tal caracterização, minimizando possíveis erros de memória.

\subsection{Análise dos dados}

Para descrição das variáveis utilizou-se a média como medida de tendência central e o desvio-padrão como informação de dispersão. Realizou-se análise univariada com o intuito de investigar associações entre as variáveis em estudo (teste Qui-quadrado) e Análise de Variância (ANOVA) para comparar as médias entre os diferentes grupos. 
Os cálculos foram realizados com o auxílio do programa Epi Info versão 6.04 (Dean et al., 1996), considerando-se nível de significância de 5\% para os testes estatísticos.

\subsection{Questöes éticas}

O presente projeto encontra-se de acordo com as normas da resolução 196 de 10/10/1996 do Conselho Nacional de Saúde, que regulamenta as pesquisas envolvendo seres humanos e foi aprovado pelo Comitê de Ética em Pesquisa da Faculdade de Saúde Pública da Universidade de Såo Paulo (Anexo IV).

Por se tratar de população vulnerável e de autonomia reduzida, solicitou-se, previamente, o consentimento livre e esclarecido da Instituição (Anexo V) e dos pais e/ ou responsáveis legais (Anexo III). 


\subsection{Caracterização do grupo estudado}

Foram convidados a participar da pesquisa cerca de 850 alunos, no entanto, apenas $35 \%$ destes individuos apresentaram o cartão referente às condições de seu nascimento. Vale ressaltar que a amostra alcançada também sofreu interferência de outros aspectos como, o caráter de liberdade e espontaneidade para a participação e pelo fato de que, individuos com excesso de peso corporal mostram-se menos interessados em participar de eventos que envolvam avaliações do estado nutricional.

A amostra final do estudo resultou em 300 estudantes, matriculados em duas escolas públicas do Município de São José dos Campos - SP, localizadas nas regiões Sul e Central, sendo 110 meninos $(36,7 \%)$ e 190 meninas $(63,3 \%)$, com média de $15,2 \pm$ 1,4 anos de idade (Tabela 01).

O colégio pertencente à região Central situava-se no interior do Centro Técnico Aeroespacial (CTA), destinado, predominantemente, a filhos de militares residentes no CTA, estudantes do periodo matutino, representando $35 \%$ da amostra $(n=105) .0$ restante da amostra compreendeu alunos dos períodos matutino, vespertino e noturno de uma escola pública no Bairro Bosque dos Eucaliptos, Zona Sul de São José dos Campos.

As informações referentes à escolaridade dos pais foram utilizadas para caracterização sócio-econômica do grupo avaliado, sendo que $23,4 \%$ dos pais e $17,9 \%$ das mães mostraram-se dentro do critério para determinação de alto nível sócio-econômico. A conclusão do Ensino Médio foi apontada por $38,5 \%$ dos pais e $36,5 \%$ das mães.

Participação nas aulas de educação física foi apontada por $55,3 \%$ dos entrevistados ( $n=166)$, sendo que os meninos mostraram-se mais ativos $(69,1 \%)$ do que as meninas (47,4\%). A prática de exercicios físicos fora do ambiente escolar, foi informada por $38,5 \%$ dos alunos, predominantemente entre os meninos $(60,5 \%)$ do que entre as meninas $(25,8 \%)$. 
O tempo direcionado à prática de atividades sedentárias como assistir televisão, utilizar computador e vídeo-game, mostrou-se elevado, sendo que em média, os meninos permaneciam $4,8 \pm 2,3$ horas/ dia nestas atividades, enquanto as meninas afirmaram utilizar $4,5 \pm 2,3$ horas do dia em atividades passivas $(p=0,449)$.

Pode-se verificar na Tabela 01 que as informaçðes referentes ao peso ao nascer e idade atual mostraram-se bastante homogêneas, não resultando em diferenças estatisticamente significativas entre os meninos e meninas. Apenas foi detectada diferença estatística entre as variáveis antropométricas atuais, que naturalmente recebem interferência hormonal e constitucional, e comprimento ao nascer.

Informações referentes ao comprimento ao nascer foram encontradas no cartão de nascimento de 287 alunos. Por este motivo, os dados referentes a esta variável e ao indice ponderal não contemplaram 13 indivíduos, resultando em uma amostra de 106 meninos e 181 meninas.

Tabela 01: Distribuição dos valores médios (desvio - padrão) da idade e variáveis antropométricas ao nascer e atuais dos jovens segundo sexo.

\begin{tabular}{lcccc}
\hline & $\begin{array}{c}\text { Meninos } \\
\text { Média (dp) }\end{array}$ & $\begin{array}{c}\text { Meninas } \\
\text { Média (dp) }\end{array}$ & $\begin{array}{c}\text { Total } \\
\text { Média (dp) }\end{array}$ & Valor de p \\
\hline Idade (anos) & $15,33(1,5)$ & $15,22(1,4)$ & $15,25(1,4)$ & 0,514 \\
Estatura (cm) & $171,50(7,4)$ & $160,63(6,0)$ & $164,62(8,4)$ & $0,000^{*}$ \\
Peso (kg) & $61,99(11,0)$ & $53,79(10,4)$ & $56,79(11,3)$ & $0,000^{*}$ \\
Circunferência & $74,88(7,7)$ & $71,12(8,1)$ & $72,50(8,2)$ & $0,000^{*}$ \\
cintura (cm) & & & & \\
Peso nascer (g) & $3281,9(528,6)$ & $3177,7(564,5)$ & $3215,9(553,0)$ & 0,115 \\
Comprimento ao & $49,2(2,6)$ & $48,5(3,0)$ & $48,8(2,9)$ & $0,043^{*}$ \\
nascer (cm) & & & & \\
İ́dice ponderal & $2,76(0,4)$ & $2,77(0,4)$ & $2,77(0,4)$ & 0,875 \\
IMC & $21,03(3,1)$ & $20,80(3,3)$ & $20,89(3,3)$ & 0,569 \\
Gordura (kg) & $8,45(4,5)$ & $16,22(7,3)$ & $13,37(7,4)$ & $0,000^{*}$ \\
$\begin{array}{l}\text { Massa muscular } \\
\text { (kg) }\end{array}$ & $26,26(5,0)$ & $17,57(2,8)$ & $20,75(5,6)$ & $0,000^{*}$ \\
\hline n=300 & & & & \\
dp = desvio- padrão & & & & \\
*diferença estatisticamente significativa & &
\end{tabular}


Informaçð̃es referentes à menarca e seu periodo de ocorrência mostraram que $96,8 \%$ $(n=184)$ das meninas vivenciaram esta experiência, que ocorreu, em média, quando apresentaram $11,96 \pm 1,2$ anos de idade.

\subsection{Estado nutricional ao nascer}

Verificou-se prevalência de $10 \%$ de bebês pequenos para idade gestacional (PIG) e de $20 \%$ de recém-nascidos grandes para idade gestacional (GIG) (Tabela 02). Os alunos do sexo masculino apresentaram maior proporção de casos PIG e GIG, quando comparados às meninas. No entanto, não se detectou diferença estatisticamente significativa entre os grupos analisados $(p=0,572)$.

Tabela 02: Distribuição dos jovens, segundo estado nutricional ao nascer e sexo.

\begin{tabular}{lcccccc}
\hline & \multicolumn{2}{c}{ Meninos } & \multicolumn{2}{c}{ Meninas } & \multicolumn{2}{c}{ Total } \\
& $\mathrm{n}$ & $\%$ & $\mathrm{n}$ & $\%$ & $\mathrm{n}$ & $\%$ \\
\hline PIG & 12 & 10,9 & 18 & 9,5 & 30 & 10,0 \\
AIG & 73 & 66,4 & 137 & 72,1 & 210 & 70,0 \\
GIG & 25 & 22,7 & 35 & 18,4 & 30 & 20,0 \\
Total & 110 & 100 & 190 & 100 & 300 & 100 \\
\hline $\mathrm{n}=300$ & & & & & &
\end{tabular}

Verificou-se índice ponderal médio de $2,76 \pm 0,4$ e $2,77 \pm 0,4$ para os meninos e meninas, respectivamente (Tabela 01). Não foram encontradas diferenças estatisticamente significativas entre a distribuiçăo dos entrevistados segundo sexo e tercis de índice ponderal $(\mathrm{p}=0,361)$, conforme descrito na Tabela 03.

Tabela 03: Distribuição dos entrevistados segundo sexo e tercis de índice ponderal.

\begin{tabular}{|c|c|c|c|c|c|c|}
\hline & \multicolumn{4}{|c|}{$\begin{array}{l}\text { Indice Ponderal } \\
2^{\circ} \text { tercil }\end{array}$} & \multicolumn{2}{|c|}{$3^{\circ}$ tercil } \\
\hline & $\mathbf{n}$ & $\%$ & $\mathbf{n}$ & $\%$ & $\mathbf{n}$ & $\%$ \\
\hline Meninos & 34 & 32,1 & 41 & 38,7 & 31 & 29,2 \\
\hline Meninas & 62 & 34,1 & 55 & 30,7 & 64 & 35,2 \\
\hline
\end{tabular}

Analisando-se a distribuição dos tercis de indice ponderal segundo estado nutricional ao nascer, observou-se consistência entre estes dois indices antropométricos (Tabela 04), uma vez que a maior proporção de individuos PIG concentraram-se no primeiro 
tercil de índice ponderal, enquanto que no $3^{\circ}$ tercil de IP detectou-se maior porcentagem de indivíduos GIG $(p=0,000)$, sendo que este comportamento mantevese semelhante para os meninos $(p=0,004)$ e meninas $(p=0,000)$.

Tabela 04: Distribuição dos entrevistados segundo tercis de índice ponderal e estado nutricional ao nascer.

\begin{tabular}{|c|c|c|c|c|c|c|}
\hline \multirow{2}{*}{$\begin{array}{c}\text { Estado nutricional } \\
\text { ao nascer }\end{array}$} & \multicolumn{2}{|c|}{$1^{\circ}$ tercil } & \multicolumn{2}{|c|}{$\begin{array}{c}\text { Indice Ponderal } \\
2^{\circ} \text { tercil }\end{array}$} & \multicolumn{2}{|c|}{$3^{\circ}$ tercil } \\
\hline & $\mathbf{n}$ & $\%$ & $\mathbf{n}$ & $\%$ & $\mathbf{n}$ & $\%$ \\
\hline PIG & 19 & 63,3 & 07 & 23,3 & 04 & 13,3 \\
\hline AIG & 74 & 37,0 & 76 & 37,5 & 51 & 25,5 \\
\hline GIG & 03 & 5,2 & 15 & 25,9 & 40 & 69,0 \\
\hline
\end{tabular}

Considerando-se apenas o valor de peso ao nascer, foram identificadas prevalências de $7,7 \%(n=23)$ de baixo peso ao nascer $(<2500 \mathrm{~g})$ e $4,3 \%(n=13)$ de alto peso ao nascer $(>4000 \mathrm{~g})$ entre os jovens estudados.

Encontrou-se prevalência de $91,6 \%$ de partos a termo (Tabela 05), não sendo observada diferença estatisticamente significativa segundo idade gestacional e sexo $(\mathrm{p}=0,619)$.

Tabela 05: Distribuição dos individuos segundo sexo e idade gestacional (meses).

\begin{tabular}{lcccccc}
\hline & \multicolumn{2}{c}{ Meninos } & \multicolumn{2}{c}{ Meninas } & \multicolumn{2}{c}{ Total } \\
& $\mathbf{n}$ & $\%$ & $\mathrm{n}$ & $\%$ & $\mathrm{n}$ & $\%$ \\
\hline 06 meses & 00 & 0,0 & 02 & 1,1 & 02 & 0,7 \\
07 meses & 03 & 2,7 & 03 & 1,6 & 06 & 2,0 \\
08 meses & 07 & 6,4 & 10 & 5,3 & 17 & 5,7 \\
09 meses & 100 & 90,9 & 175 & 92,1 & 275 & 91,6 \\
Total & 110 & 100 & 190 & 100 & 300 & 100 \\
\hline $\mathbf{n}=300$ & & & & & &
\end{tabular}

Diferença estatisticamente significativa foi detectada entre prematuridade e estado nutricional ao nascer $(\mathrm{p}=0,007)$, verificando-se que $23,3 \%$ dos indivíduos PIG nasceram com idade gestacional inferior a 37 semanas (Tabela 06). 
Tabela 06: Distribuição dos entrevistados segundo estado nutricional ao nascer e prematuridade.

\begin{tabular}{lccccc}
\hline Estado nutricional ao nascer & \multicolumn{3}{c}{ Prematuridade } \\
& Sim & & Não & n & $(\%)$ \\
\hline PIG & 07 & 23,3 & 23 & 76,7 \\
AIG & 14 & 6,7 & 196 & 93,3 \\
GIG & 04 & 6,7 & 56 & 93,3 \\
\hline$n=300$ & & & &
\end{tabular}

$\mathrm{n}=300$

Segundo informação obtida junto aos responsáveis pelos alunos, $88,2 \%$ foram alimentados com leite materno, verificando-se, praticamente, a mesma proporção de casos no sexo masculino $(88,5 \%)$ e feminino $(88,1 \%)(p=0,935)$.

\subsection{Estado nutricional atual}

Conforme se observa na Tabela $07,14,7 \%$ e $2,3 \%$ dos entrevistados apresentaram sobrepeso e obesidade, respectivamente. As meninas mostraram maior prevalência de obesidade (2,6\%), quando comparadas aos meninos, enquanto maior ocorrência de sobrepeso foi diagnosticada entre os alunos do sexo masculino $(18,2 \%)$, fato que pode ser explicado por um conteúdo maior de massa muscular (Tabela 01), uma vez que o IMC não diferencia a composição corporal.

Tabela 07: Distribuição dos indivíduos (número e \%) segundo sexo e diagnóstico nutricional atual.

\begin{tabular}{|c|c|c|c|c|c|c|c|}
\hline \multirow{2}{*}{$\begin{array}{l}\text { Diagnóstico } \\
\text { nutricional }\end{array}$} & \multicolumn{2}{|c|}{ Meninos } & \multicolumn{2}{|c|}{ Meninas } & \multicolumn{2}{|c|}{ Total } & \multirow[t]{2}{*}{ Valor de $p$} \\
\hline & $\mathrm{n}$ & $\%$ & $\mathrm{n}$ & $\%$ & $\mathbf{n}$ & $\%$ & \\
\hline Sobrepeso & 20 & 18,2 & 24 & 12,6 & 44 & 14,7 & 0,254 \\
\hline Obesidade & 01 & 1,8 & 05 & 2,6 & 07 & 2,3 & 0,957 \\
\hline Baixa estatura & 04 & 3,6 & 13 & 6,8 & 17 & 5,7 & 0,369 \\
\hline $\begin{array}{l}\text { Acúmulo de gordura } \\
\text { abdominal }\end{array}$ & 24 & 21,8 & 69 & 36,3 & 93 & 31,0 & $0,012^{*}$ \\
\hline $\begin{array}{l}\text { Gordura corporal } \\
\text { acima do adequado }\end{array}$ & 02 & 1,8 & 58 & 30,5 & 60 & 20 & $0,000^{*}$ \\
\hline $\begin{array}{l}\text { Massa magra abaixo } \\
\text { do adequado }\end{array}$ & 06 & 5,5 & 62 & 32,6 & 68 & 22,7 & $0,000^{*}$ \\
\hline
\end{tabular}


Com relação à localização da gordura corporal, verificou-se acúmulo excessivo de gordura na região abdominal em $31 \%$ do grupo analisado (Tabela 07), sendo esta caracteristica presente com maior intensidade nos individuos do sexo feminino $(36,3 \%)$, grupo que também apresentou maior prevalência de massa magra reduzida e excesso de gordura e peso corporal $(p<0,05)$.

\subsection{Relação entre estado nutricional ao nascer e atual}

\subsection{1 Índice ponderal e estado nutricional atual}

Dividindo-se o grupo segundo tercis de índice ponderal (IP), pode-se verificar que os valores médios de peso ao nascer elevam-se conforme aumenta o indice ponderal, enquanto que os valores médios de comprimento ao nascer mostraram comportamento inverso (Tabela 08), sugerindo que o grupo pertencente ao primeiro tercil sofreu restrição nutricional no final do periodo gestacional, preservando o crescimento linear e resultando em bebês desproporcionados, ao passo que o grupo pertencente ao último tercil poderia ter sofrido restriç̃es no início da gestação, acarretando em prejuizo no comprimento final. Comportamento semelhante foi identificado em relação à estatura atual, ou seja, o grupo pertencente ao último tercil de índice ponderal apresentou, em média, valor inferior de estatura

Com relação ao diagnóstico do estado nutricional atual segundo tercil de IP, não foram identificadas diferenças estatisticamente significativas entre os grupos (Tabela 09), no entanto, o grupo pertencente ao último tercil de índice ponderal apresentou maior prevalência de sobrepeso, acúmulo de gordura na região abdominal e quantidade de massa magra abaixo do adequado, enquanto que os indivíduos do primeiro tercil mostraram maior ocorrência de quantidade de gordura corporal acima do adequado. 
Tabela 08: Distribuição das variáveis demográficas e antropométricas dos jovens, segundo tercis de índice ponderal.

\begin{tabular}{lcccc}
\hline & \multicolumn{3}{c}{ Tercis de Indice Ponderal } & \\
& $1^{\circ}$ Tercil & $2^{\circ}$ Tercil & $3^{\circ}$ Tercil & Valor de p \\
\hline Idade (anos) & $15,45(1,5)$ & $15,07(1,3)$ & $15,16(1,5)$ & 0,114 \\
Estatura (cm) & $165,72(8,9)$ & $164,84(8,2)$ & $163,39(8,0)$ & 0,153 \\
Peso (kg) & $57,46(12,2)$ & $56,92(10,5)$ & $56,28(11,7)$ & 0,777 \\
Indice Ponderal & $2,37(0,2)$ & $2,74(0,1)$ & $3,20(0,4)$ & $0,000^{*}$ \\
Peso ao nascer (g) & $2934,1(512,5)$ & $3237,9(413,4)$ & $3479,4(535,0)$ & $0,000^{*}$ \\
Comprimento (cm) & $49,62(2,6)$ & $48,98(2,1)$ & $47,70(3,5)$ & $0,000^{*}$ \\
IMC & $20,85(3,5)$ & $20,89(3,1)$ & $20,97(3,3)$ & 0,966 \\
Circunferência da & $72,22(8,0)$ & $72,47(8,3)$ & $72,94(8,6)$ & 0,831 \\
cintura (cm) & & & & \\
Idade gestacional & $8,83(0,5)$ & $8,91(0,3)$ & $8,93(0,4)$ & 0,195 \\
(meses) & & $12,70(6,9)$ & $13,55(6,8)$ & 0,487 \\
$\begin{array}{l}\text { Gordura corporal } \\
\text { (kg) }\end{array}$ & $13,97(8,5)$ & & & \\
Massa magra (kg) & $21,07(5,5)$ & $21,08(5,7)$ & $20,18(5,9)$ & 0,450 \\
\hline n=287 & & &
\end{tabular}

Tabela 09: Distribuição dos jovens segundo tercis de indice ponderal e diagnóstico do estado nutricional atual.

\begin{tabular}{|c|c|c|c|c|c|c|c|}
\hline \multirow[t]{3}{*}{ Diagnóstico nutricional } & \multicolumn{7}{|c|}{ Tercis de Índice Ponderal } \\
\hline & \multicolumn{2}{|c|}{$1^{\circ}$ Tercil } & \multicolumn{2}{|c|}{$2^{\circ}$ Tercil } & \multicolumn{2}{|c|}{$3^{\circ}$ Tercil } & \multirow[t]{2}{*}{ Valor de p } \\
\hline & $\mathbf{n}$ & $\%$ & $\mathbf{n}$ & $\%$ & $\mathbf{n}$ & $\%$ & \\
\hline Sobrepeso & 10 & 10,4 & 15 & 15,5 & 17 & 17,9 & 0,327 \\
\hline Obesidade & 02 & 2,1 & 02 & 2,1 & 03 & 3,2 & 0,854 \\
\hline Baixa estatura & 04 & 25,0 & 06 & 37,5 & 06 & 37,5 & 0,767 \\
\hline $\begin{array}{l}\text { Acúmulo de gordura } \\
\text { abdominal }\end{array}$ & 29 & 30,2 & 28 & 28,9 & 34 & 35,8 & 0,551 \\
\hline $\begin{array}{l}\text { Gordura corporal acima do } \\
\text { adequado }\end{array}$ & 24 & 25,0 & 15 & 15,5 & 18 & 18,9 & 0,243 \\
\hline $\begin{array}{l}\text { Massa magra abaixo do } \\
\text { adequado }\end{array}$ & 21 & 21,9 & 22 & 22,7 & 23 & 24,2 & 0,927 \\
\hline
\end{tabular}

Quanto à prática alimentar no início da vida, não foram observadas diferenças estatisticamente significativas em relação à oferta de leite humano segundo tercis de indice ponderal $(p=0,264)$, resultando em prevalências de $86,4 \%$ no primeiro tercil de IP, 93,1\% naqueles pertencentes ao tercil intermediário e $86,2 \%$ entre os individuos situados no último tercil. 
Não foram encontradas diferenças estatisticamente significativas entre a prática de atividades passivas de lazer e índice ponderal $(p=0,860)$. Os jovens com baixo indice ponderal afirmaram permanecer, em média $4,67 \pm 2,4$ horas/ dia em atividades passivas, enquanto que os pertencentes aos grupos de índice ponderal intermediário e alto índice ponderal responderam que destinam, em média, 4,52 $\pm 2,3$ e 4,68 $\pm 2,2$ horas do dia, respectivamente, para estes passatempos.

Achado semelhante foi identificado em relação à prática de atividade física fora do ambiente escolar $(p=0,105)$ e participação nas aulas de educação física $(p=0,373)$, segundo categorias de indice ponderal. Os alunos com alto índice ponderal mostraram menor prática de atividade física fora do ambiente escolar (69,5\%), quando comparados aos que nasceram com baixo índice ponderal $(60,7 \%)$ e indice ponderal intermediário $(54,6 \%)$.

Estratificando-se o grupo segundo sexo, observou-se, em média, valor superior de estatura entre os meninos pertencentes ao primeiro tercil de indice ponderal e valores superiores de peso, circunferência da cintura, quantidade de gordura corporal e quantidade de massa muscular entre os meninos do último tercil de índice ponderal (Tabela 10).

Tabela 10: Distribuição das variáveis demográficas e antropométricas dos meninos, segundo tercis de indice ponderal.

\begin{tabular}{|c|c|c|c|c|}
\hline \multicolumn{5}{|c|}{ Tercis de Índice Ponderal } \\
\hline & $1^{\circ}$ Tercil & $2^{\circ}$ Tercil & $3^{\circ}$ Tercil & Valor de \\
\hline Idade (anos) & $15,62(1,6)$ & $15,15(1,4)$ & $15,23(1,3)$ & 0,355 \\
\hline Estatura $(\mathrm{cm})$ & $173,25(8,4)$ & $169,86(8,1)$ & $171,63(4,9)$ & 0,149 \\
\hline Peso (kg) & $61,28(10,4)$ & $61,19(10,9)$ & $64,41(12,3)$ & 0,415 \\
\hline Índice Ponderal & $2,37(0,2)$ & $2,74(0,1)$ & $3,23(0,5)$ & $0,000^{*}$ \\
\hline IMC & $20,35(2,5)$ & $21,17(3,2)$ & $21,82(3,6)$ & 0,176 \\
\hline $\begin{array}{l}\text { Circunferência da } \\
\text { cintura (cm) }\end{array}$ & $73,44(5,2)$ & $74,86(8,3)$ & $76,95(9,0)$ & 0,189 \\
\hline $\begin{array}{l}\text { Idade gestacional } \\
\text { (meses) }\end{array}$ & $8,85(0,4)$ & $8,85(0,4)$ & $9,00(0,0)$ & 0,168 \\
\hline $\begin{array}{l}\text { Gordura corporal } \\
(\mathrm{kg})\end{array}$ & $8,15(3,7)$ & $8,03(4,4)$ & $9,55(5,5)$ & 0,322 \\
\hline Massa magra (kg) & $26,08(5,2)$ & $25,97(5,0)$ & $27,03(5,2)$ & 0,654 \\
\hline
\end{tabular}


Com relação ao diagnóstico do estado nutricional segundo índice ponderal, encontrou-se maior prevalência de sobrepeso $(\mathrm{p}=0,051)$, acúmulo de gordura na região abdominal $(\mathrm{p}=0,038)$ nos meninos pertencentes ao último tercil de índice ponderal (Tabela 11).

Tabela 11: Distribuição dos meninos segundo tercis de índice ponderal e diagnóstico do estado nutricional atual.

\begin{tabular}{|c|c|c|c|c|c|c|c|}
\hline \multirow[t]{3}{*}{ Diagnóstico nutricional } & \multicolumn{7}{|c|}{ Tercis de Índice Ponderal } \\
\hline & \multicolumn{2}{|c|}{$1^{\circ}$ Tercil } & \multicolumn{2}{|c|}{$2^{\circ}$ Tercil } & \multicolumn{2}{|c|}{$3^{\circ}$ Tercil } & \multirow[t]{2}{*}{ Valor de $\mathrm{p}$} \\
\hline & $\mathbf{n}$ & $\%$ & $\mathrm{n}$ & $\%$ & $\mathbf{n}$ & $\%$ & \\
\hline Sobrepeso & 03 & 8,8 & 07 & 17,1 & 10 & 32,3 & $0,051^{*}$ \\
\hline Obesidade & 00 & 0,0 & 01 & 2,4 & 01 & 3,2 & 0,600 \\
\hline $\begin{array}{l}\text { Acúmulo de gordura } \\
\text { abdominal }\end{array}$ & 05 & 14,7 & 07 & 17,1 & 12 & 38,7 & $0,038^{*}$ \\
\hline $\begin{array}{l}\text { Gordura corporal acima do } \\
\text { adequado }\end{array}$ & 00 & 0,0 & 01 & 2,4 & 01 & 3,2 & 0,600 \\
\hline $\begin{array}{l}\text { Massa magra abaixo do } \\
\text { adequado }\end{array}$ & 03 & 8,8 & 02 & 4,9 & 01 & 3,2 & 0,598 \\
\hline
\end{tabular}

Conforme descrito na tabela 12 , verificou-se diferença estatisticamente significativa entre os valores médios da quantidade de massa muscular segundo índice ponderal entre as meninas $(p=0,012)$, sendo que o grupo pertencente ao primeiro tercil mostrou valor superior desta variável antropométrica, enquanto que o inverso foi encontrado nas meninas de maior índice ponderal, grupo que também apresentou, em média, valor inferior de estatura $(p=0,096)$.

Com relação ao diagnóstico do estado nutricional atual das meninas segundo índice ponderal, observou-se maior prevalência de quantidade de gordura corporal acima do adequado entre aquelas pertencentes ao primeiro tercil de índice ponderal, no entanto, sem significância estatística (Tabela 13). 
Tabela 12: Distribuição das variáveis demográficas e antropométricas das meninas, segundo tercis de índice ponderal.

\begin{tabular}{lcccc}
\hline & \multicolumn{3}{c}{ Tercis de Índice Ponderal } & \\
& $1^{\circ}$ Tercil & $2^{\circ}$ Tercil & $3^{\circ}$ Tercil & Valor de p \\
\hline Idade (anos) & $15,40(1,4)$ & $15,02(1,2)$ & $15,12(1,5)$ & 0,302 \\
Estatura (cm) & $161,60(6,0)$ & $161,17(6,1)$ & $159,41(5,8)$ & 0,096 \\
$\begin{array}{l}\text { Peso }(\mathrm{kg}) \\
\text { Índice Ponderal }\end{array}$ & $55,36(12,7)$ & $53,79(9,1)$ & $52,34(9,2)$ & 0,275 \\
IMC & $2,37(0,2)$ & $2,74(0,1)$ & $3,19(0,4)$ & $0,000^{*}$ \\
$\begin{array}{l}\text { Circunferência da } \\
\text { cintura (cm) }\end{array}$ & $21,12(3,9)$ & $20,69(3,1)$ & $20,56(3,1)$ & 0,630 \\
$\begin{array}{l}\text { Idade gestacional } \\
\text { (meses) }\end{array}$ & $71,55(9,1)$ & $70,72(7,9)$ & $71,00(7,8)$ & 0,857 \\
$\begin{array}{l}\text { Gordura corporal } \\
\text { (kg) }\end{array}$ & $17,82(0,5)$ & $8,95(0,2)$ & $8,90(0,5)$ & 0,280 \\
Massa magra $(\mathrm{kg})$ & $18,33(3,3)$ & $17,50(2,7)$ & $16,86(2,1)$ & $0,012^{*}$ \\
\hline
\end{tabular}

* diferença estatisticamente significativa

Tabela 13: Distribuição das meninas segundo tercis de índice ponderal e diagnóstico do estado nutricional atual.

\begin{tabular}{|c|c|c|c|c|c|c|c|}
\hline \multirow[t]{3}{*}{ Diagnóstico nutricional } & \multicolumn{7}{|c|}{ Tercis de Índice Ponderal } \\
\hline & \multicolumn{2}{|c|}{$1^{\circ}$ Tercil } & \multicolumn{2}{|c|}{$2^{\circ}$ Tercil } & \multicolumn{2}{|c|}{$3^{\circ}$ Tercil } & \multirow[t]{2}{*}{ Valor de $p$} \\
\hline & $\mathbf{n}$ & $\%$ & $\mathbf{n}$ & $\%$ & $\mathbf{n}$ & $\%$ & \\
\hline Sobrepeso & 07 & 11,3 & 08 & 14,3 & 07 & 10,9 & 0,830 \\
\hline Obesidade & 02 & 3,2 & 01 & 1,8 & 02 & 3,1 & 0,869 \\
\hline $\begin{array}{l}\text { Acúmulo de gordura } \\
\text { abdominal }\end{array}$ & 24 & 38,7 & 21 & 37,5 & 22 & 34,4 & 0,873 \\
\hline $\begin{array}{l}\text { Gordura corporal acima do } \\
\text { adequado }\end{array}$ & 24 & 38,7 & 14 & 25,0 & 17 & 26,6 & 0,197 \\
\hline $\begin{array}{l}\text { Massa magra abaixo do } \\
\text { adequado }\end{array}$ & 18 & 29,0 & 20 & 35,7 & 22 & 34,4 & 0,711 \\
\hline
\end{tabular}

\subsubsection{Estado nutricional ao nascer e atual}

Conforme descrito na Tabela 14, os indivíduos grandes para idade gestacional (GIG), apresentaram valores médios superiores de estatura, peso, circunferência da cintura e quantidade de massa muscular, quando comparados às demais categorias de estado nutricional ao nascer.

Os valores médios de indice ponderal apresentados na Tabela 14 mostram consistência com 0 aumento de peso ao nascer segundo idade gestacional, 
representado entre os grupos de indivíduos pequenos, adequados e grandes para idade gestacional.

Não foram encontradas diferenças estatisticamente significativas entre a prática de atividades passivas de lazer $e$ as diferentes categorias de estado nutricional ao nascer $(p=0,691)$. Os jovens pequenos para idade gestacional (PIG) afirmaram permanecer, em média 4,96 $\pm 2,8$ horas/ dia em atividades passivas, enquanto que os pertencentes aos grupos AIG e GIG responderam que destinam, em média, 4,61 $\pm 2,3$ e 4,52 $\pm 2,1$ horas do dia, respectivamente, para estes passatempos.

Resultado semelhante foi identificado em relação à prática de atividade física fora do ambiente escolar $(p=0,593)$ e participação nas aulas de educação física $(p=0,431)$, segundo categorias de estado nutricional ao nascer.

Verificou-se diferença estatisticamente significativa entre o nivel de escolaridade da mãe e estado nutricional ao nascer $(\mathrm{p}=0,049)$. Conforme esperado para época em que nasceram os entrevistados, observou-se maior prevalência de alto nível sócioeconômico entre os individuos GIG (20,0\%), quando comparados aos AIG $(17,1 \%)$ e PIG $(11,2 \%)$. Não foi identificada diferença significativa em relação à escolaridade dos pais $(\mathrm{p}=0,342)$.

Quanto à prática alimentar no início da vida, não foram observadas diferenças estatisticamente significativas em relação à oferta de leite humano e estado nutricional ao nascer $(p=0,658)$, resultando em prevalências de $85,7 \%$ no grupo PIG, $89,4 \%$ naqueles que nasceram com peso adequado para idade gestacional e $85,4 \%$ entre os indivíduos GIG.

Com relação ao diagnóstico nutricional atual segundo categorias de estado nutricional ao nascer, verificou-se maior proporção de indivíduos com quantidade de massa muscular abaixo do adequado entre o grupo PIG, enquanto que o grupo GIG apresentou maior prevalência de acúmulo de gordura na região abdominal (Tabela 15), no entanto sem significância estatística. 
Tabela 14: Distribuição das variáveis demográficas e antropométricas dos indivíduos (média \pm desvio - padrão) segundo categorias de peso ao nascer.

\begin{tabular}{lcccc}
\hline & PIG & AIG & GIG & Valor de p \\
& Média (dp) & Média (dp) & Média (dp) & \\
\hline Idade (anos) & $15,83(1,5)$ & $15,20(1,4)$ & $15,15(1,4)$ & 0,063 \\
Estatura (cm) & $163,70(8,1)$ & $164,23(8,3)$ & $166,43(8,6)$ & 0,166 \\
Peso (kg) & $56,47(10,6)$ & $56,18(11,5)$ & $59,09(10,8)$ & 0,213 \\
Circunferência & $73,19(9,5)$ & $71,92(8,0)$ & $74,19(7,8)$ & 0,147 \\
cintura (cm) & & & & \\
Peso ao nascer (g) & $2408,5(394,4)$ & $3141,6(361,9)$ & $3879,7(458,3)$ & $0,000^{*}$ \\
Comprimento (cm) & $45,8(4,1)$ & $48,9(2,2)$ & $49,9(3,2)$ & $0,000^{*}$ \\
Indice ponderal & $2,55(0,5)$ & $2,71(0,4)$ & $3,09(0,4)$ & $0,000^{*}$ \\
IMC & $21,09(3,6)$ & $20,75(3,3)$ & $21,27(2,9)$ & 0,524 \\
Gordura corporal & $13,44(8,8)$ & $13,36(7,4)$ & $13,35(6,7)$ & 0,998 \\
(kg) & & & & \\
Massa muscular & $20,53(5,0)$ & $20,39(5,2)$ & $22,13(7,0)$ & 0,102 \\
(kg) & & & & \\
\hline n= 300 & & & &
\end{tabular}

Tabela 15: Distribuição dos individuos (número e \%) segundo classificação do estado nutricional ao nascer e diagnóstico nutricional atual.

\begin{tabular}{|c|c|c|c|c|c|c|c|}
\hline & \multicolumn{2}{|c|}{ PIG } & \multicolumn{2}{|c|}{ AIG } & \multicolumn{2}{|c|}{ GIG } & \multirow{2}{*}{$\begin{array}{c}\text { Valor de } \\
p\end{array}$} \\
\hline & $\mathbf{n}$ & $\%$ & $\mathbf{n}$ & $\%$ & $\mathbf{n}$ & $\%$ & \\
\hline Sobrepeso & 06 & 20,0 & 27 & 12,8 & 11 & 18,3 & 0,391 \\
\hline Obesidade & 01 & 3,3 & 05 & 2,4 & 01 & 1,6 & 0,882 \\
\hline Baixa estatura & 04 & 23,6 & 11 & 64,7 & 02 & 11,9 & 0,136 \\
\hline $\begin{array}{l}\text { Acúmulo de gordura } \\
\text { abdominal }\end{array}$ & 07 & 23,3 & 65 & 30,9 & 21 & 35,0 & 0,529 \\
\hline $\begin{array}{l}\text { Gordura corporal acima } \\
\text { do adequado }\end{array}$ & 05 & 16,7 & 44 & 21,0 & 11 & 18,3 & 0,806 \\
\hline $\begin{array}{l}\text { Massa magra abaixo do } \\
\text { adequado }\end{array}$ & 08 & 26,7 & 47 & 22,4 & 13 & 21,7 & 0,853 \\
\hline
\end{tabular}

Estratificando-se a amostra por sexo, verificou-se que para o sexo masculino o fato de nascer GIG parece relacionar-se com maior predisposição para apresentação de um fenótipo robusto no futuro. Os meninos pertencentes ao grupo GIG mostraram valores médios superiores de circunferência da cintura $(p=0,083)$ quando comparados aos PIG e AIG, sendo que os valores médios de circunferência da cintura aumentaram conforme peso ao nascer segundo idade gestacional (Tabela 16). 
As mesmas características foram observadas em relação às outras variáveis antropométricas, como estatura $(p=0,090)$, peso corporal $(p=0,065)$, IMC $(p=$ $0,315)$, quantidade de gordura corporal $(p=0,321)$ e massa muscular $(p=0,009)$.

Tabela 16: Distribuição das variáveis demográficas e antropométricas dos indivíduos do sexo masculino (média \pm desvio - padrão) segundo estado nutricional ao nascer.

\begin{tabular}{lcccc}
\hline & PIG & AIG & GIG & Valor de p \\
& Média (dp) & Média (dp) & Média (dp) & \\
\hline Idade (anos) & $15,42(1,4)$ & $15,34(1,4)$ & $15,24(1,6)$ & 0,932 \\
Estatura (cm) & $168,70(6,4)$ & $171,11(7,9)$ & $174,01(5,6)$ & 0,090 \\
Peso $(\mathrm{kg})$ & $57,42(8,9)$ & $61,39(11,5)$ & $65,90(9,6)$ & 0,065 \\
Circunferência cintura (cm) & $71,57(5,1)$ & $74,58(7,9)$ & $77,36(7,3)$ & 0,083 \\
Peso ao nascer (g) & 2491,1 & 3185,6 & 3942,8 & $0,000^{*}$ \\
& $(369,6)$ & $(342,9)$ & $(240,9)$ & \\
Comprimento (cm) & $45,92(3,0)$ & $49,29(2,2)$ & $50,67(1,9)$ & $0,000^{*}$ \\
Indice ponderal & $2,59(0,4)$ & $2,70(0,4)$ & $3,05(0,4)$ & $0,001^{*}$ \\
IMC & $20,17(2,8)$ & $20,92(3,3)$ & $21,76(2,7)$ & 0,315 \\
Gordura corporal $(\mathrm{kg})$ & $6,67(3,3)$ & $8,54(4,9)$ & $9,03(3,8)$ & 0,321 \\
Massa muscular $(\mathrm{kg})$ & $24,62(4,6)$ & $25,65(4,5)$ & $28,84(5,6)$ & $0,009^{*}$ \\
\hline n=110 & & & &
\end{tabular}
$\mathbf{n}=110$

* diferença estatisticamente significativa

Para os indivíduos do sexo feminino, verificou-se que o peso ao nascer comporta-se de modo diferente. Meninas PIG (Tabela 17), apresentaram valores médios superiores de circunferência da cintura, peso corporal, IMC e quantidade de gordura corporal, quando comparadas aos grupos AIG e GIG, no entanto, tais achados não mostraram significância estatistica. Vale ressaltar que as meninas GIG apresentaram valores médios destas variáveis antropométricas ligeiramente superiores aos verificados no grupo AIG.

Tais achados resultaram em prevalências elevadas de sobrepeso entre os meninos GIG (Tabela 18) e entre todas as variáveis que representam excesso de peso corporal nas meninas pertencentes aos extremos de peso ao nascer (Tabela 19). 
Tabela 17: Distribuição das variáveis demográficas e antropométricas dos alunos do sexo feminino (média \pm desvio - padrão) segundo categorias de peso a nascer.

\begin{tabular}{lcccc}
\hline & PIG & AIG & GIG & Valor de p \\
& Média (dp) & Média (dp) & Média (dp) & \\
\hline Idade (anos) & $16,11(1,6)$ & $15,13(1,4)$ & $15,09(1,3)$ & $0,017^{*}$ \\
Estatura (cm) & $160,37(7,5)$ & $160,57(5,9)$ & $161,02(6,0)$ & 0,909 \\
Peso (kg) & $55,83(11,8)$ & $53,41(10,6)$ & $54,23(8,9)$ & 0,627 \\
Circunferência cintura (cm) & $74,27(11,6)$ & $70,51(7,7)$ & $71,92(7,5)$ & 0,149 \\
Peso ao nascer (g) & 2353,5 & 3118,2 & 3834,6 & $0,000^{*}$ \\
& $(411,1)$ & $(370,8)$ & $(564,3)$ & \\
Comprimento (cm) & $45,67(4,8)$ & $48,67(2,1)$ & $49,44(3,8)$ & $0,000^{*}$ \\
Indice ponderal & $2,53(0,6)$ & $2,72(0,4)$ & $3,12(0,4)$ & $0,000^{*}$ \\
IMC & $21,71(4,0)$ & $20,66(3,3)$ & $20,92(3,1)$ & 0,446 \\
Gordura (kg) & $17,95(8,4)$ & $15,93(7,3)$ & $16,44(6,6)$ & 0,536 \\
Massa muscular (kg) & $17,80(3,0)$ & $17,59(2,8)$ & $17,35(2,6)$ & 0,834 \\
Menarca (anos) & $11,65(1,0)$ & $12,01(1,3)$ & $11,91(0,9)$ & 0,503 \\
\hline
\end{tabular}

* diferença estatisticamente significativa

Tabela 18: Distribuição dos meninos segundo estado nutricional ao nascer e diagnóstico nutricional atual.

\begin{tabular}{|c|c|c|c|c|c|c|c|}
\hline \multirow[t]{2}{*}{ Diagnóstico nutricional } & \multicolumn{2}{|c|}{ PIG } & \multicolumn{2}{|c|}{ AIG } & \multicolumn{2}{|c|}{ GIG } & \multirow[t]{2}{*}{ Valor de $\mathrm{p}$} \\
\hline & $\mathbf{n}$ & $\%$ & $\mathbf{n}$ & $\%$ & $\mathbf{n}$ & $\%$ & \\
\hline Sobrepeso & 02 & 16,7 & 12 & 16,4 & 06 & 24,0 & 0,692 \\
\hline Obesidade & 00 & 0,0 & 02 & 2,7 & 00 & 0,0 & 0,597 \\
\hline Acúmulo de gordura abdominal & 00 & 0,0 & 18 & 24,6 & 06 & 24,0 & 0,152 \\
\hline $\begin{array}{l}\text { Gordura corporal acima do } \\
\text { adequado }\end{array}$ & 00 & 0,0 & 02 & 2,7 & 00 & 0,0 & 0,597 \\
\hline $\begin{array}{l}\text { Massa magra abaixo do } \\
\text { adequado }\end{array}$ & 01 & 8,3 & 05 & 6,8 & 00 & 0,0 & 0,385 \\
\hline
\end{tabular}

Tabela 19: Distribuição das meninas segundo estado nutricional ao nascer, diagnóstico nutricional atual e menarca.

\begin{tabular}{|c|c|c|c|c|c|c|c|}
\hline & \multicolumn{2}{|c|}{ PIG } & \multicolumn{2}{|c|}{ AIG } & \multicolumn{2}{|c|}{ GIG } & \multirow[t]{2}{*}{ Valor de p } \\
\hline & $\mathrm{N}$ & $\%$ & $\mathbf{n}$ & $\%$ & $\mathbf{n}$ & $\%$ & \\
\hline Sobrepeso & 04 & $\overline{22,2}$ & 15 & 10,9 & 05 & 14,3 & 0,379 \\
\hline Obesidade & 01 & 5,5 & 03 & 2,2 & 01 & 2,8 & 0,700 \\
\hline $\begin{array}{l}\text { Acúmulo de gordura } \\
\text { abdominal }\end{array}$ & 07 & 38,9 & 47 & 34,3 & 15 & 42,8 & 0,625 \\
\hline Menarca & 17 & 94,4 & 133 & 97,1 & 34 & 97,1 & 0,829 \\
\hline $\begin{array}{l}\text { Gordura corporal acima } \\
\text { do adequado }\end{array}$ & 05 & 27,8 & 42 & 30,7 & 11 & 31,4 & 0,961 \\
\hline $\begin{array}{l}\text { Massa magra abaixo do } \\
\text { adequado }\end{array}$ & 07 & 38,9 & 42 & 30,7 & 13 & 37,1 & 0,641 \\
\hline
\end{tabular}


Não foram detectadas diferenças estatisticamente significativas entre as variáveis antropométricas atuais e prematuridade nos individuos pequenos para idade gestacional (Tabela 20).

Devido ao reduzido número de observações referentes aos individuos PIG e prematuros não foi possivel estratificar o grupo segundo sexo, portanto, pode-se sugerir que os valores elevados de estatura, circunferência da cintura, peso e quantidade de massa muscular e de gordura corporal identificados nos entrevistados PIG e prematuros devem-se às características antropométricas típicas entre meninos e meninas. Vale ressaltar que $42,9 \%$ dos prematuros pequenos para idade gestacional e $39,1 \%$ dos PIG nascidos a termo pertenciam ao sexo masculino.

Tabela 20: Distribuição das variáveis demográficas e antropométricas dos alunos pequenos para idade gestacional (média \pm desvio - padrão) segundo prematuridade.

\begin{tabular}{lccc}
\hline & $\begin{array}{c}\text { Pré- termo } \\
\text { Média (dp) }\end{array}$ & $\begin{array}{c}\text { Termo } \\
\text { Média (dp) }\end{array}$ & Valor de p \\
\hline Idade (anos) & $16,00(1,1)$ & $15,78(1,6)$ & 0,749 \\
Estatura (cm) & $167,07(10,2)$ & $162,67(7,3)$ & 0,215 \\
Peso (kg) & $60,11(12,0)$ & $55,36(10,2)$ & 0,307 \\
Circunferência cintura (cm) & $76,57(8,5)$ & $72,16(9,8)$ & 0,291 \\
Índice ponderal & $2,44(0,9)$ & $2,59(0,3)$ & $0,047^{*}$ \\
IMC & $21,48(3,4)$ & $20,98(3,8)$ & 0,757 \\
Gordura (kg) & $14,33(7,4)$ & $13,17(9,3)$ & 0,766 \\
Massa muscular $(\mathrm{kg})$ & $22,57(7,1)$ & $19,90(4,2)$ & 0,222 \\
\hline
\end{tabular}

* diferença estatisticamente significativa

Do mesmo modo, não foram identificadas diferenças estatisticamente significativas entre o diagnóstico do estado nutricional atual e prematuridade entre os indivíduos PIG (Tabela 21). 
Tabela 21: Distribuição dos indivíduos pequenos para idade gestacional segundo diagnóstico do estado nutricional atual e prematuridade.

\begin{tabular}{lcccccc}
\hline \multicolumn{1}{c}{ Diagnóstico do estado nutricional } & \multicolumn{3}{c}{ PIG } & \multicolumn{2}{c}{ Valor de $\mathbf{p}$} \\
& Pré- termo & Termo & \\
& $\mathrm{n}$ & $\%$ & $\mathrm{n}$ & $\%$ & \\
\hline Sobrepeso & 02 & 28,6 & 04 & 17,4 & 0,914 \\
Obesidade & 00 & 0,0 & 01 & 4,3 & 0,521 \\
Acúmulo de gordura abdominal & 02 & 28,6 & 05 & 21,7 & 0,892 \\
Gordura corporal acima do adequado & 01 & 14,3 & 04 & 17,4 & 0,699 \\
Massa magra abaixo do adequado & 01 & 14,3 & 07 & 30,4 & 0,720 \\
\hline $\mathrm{n}=30$ & & & & &
\end{tabular}


6. DISCUSSÃO 


\subsection{Consistência dos dados:}

Embora o fato de grande proporção dos alunos não possuírem mais o cartão referente às condições de seu nascimento resultar em tamanho reduzido da amostra, os achados referentes às prevalências de baixo peso ao nascer e sobrepeso mostraram consistência com dados disponíveis na literatura cientifica brasileira.

Considerando-se apenas o peso de nascimento, foram identificadas prevalências de $7,7 \%$ e $4,3 \%$ de baixo e alto peso ao nascer no grupo estudado, respectivamente, sendo que a média de peso ao nascer correspondeu a $3216 \pm 553$ gramas. Com relação a prematuridade, encontrou-se que $8,4 \%$ dos individuos nasceram com idade gestacional inferior a 37 semanas.

Devido às dificuldades para obtenção correta da idade gestacional e ao fato de que, em países em desenvolvimento, a maioria dos casos de baixo peso ao nascer deve-se ao crescimento intra -uterino restrito (RCIU) e não a prematuridade, pode-se considerar o baixo peso a nascer como um indicador válido para investigaça de RCIU (Allen \& Gillespie, 2001; Kramer, 2003).

Em paises em desenvolvimento, encontra-se prevalência média de baixo peso ao nascer de $16,4 \%$, sendo a região Centro-Sul da Ásia a área onde o problema apresenta-se com maior intensidade (Allen \& Gillespie, 2001). Valores menos alarmantes são verificados em paises desenvolvidos, como a Noruega e Suécia, onde a prevalência de baixo peso ao nascer mostra-se entre 4,0 e 6,0\% (UNICEF, 1998).

Informações sobre a prevalência de baixo peso ao nascer na população brasileira no final da década de 80 (Pesquisa Nacional sobre Saúde e Nutrição - PNSN, 1989) e início dos anos 90 (Pesquisa Nacional sobre Demografia e Saúde - PNDS, 1996), aproximadamente na época em que nasceram os indivíduos que participaram do estudo, indicam valores próximos a 9,0\% (Monteiro, 2000). 
Resultados de uma amostra probabilística de menores de dois anos de idade no Município de São Paulo em meados da década de 80 mostraram prevalência de baixo peso ao nascer de $7,9 \%$, enquanto que, as declarações de nascidos vivos do Município de São Paulo em 1998 apontaram para prevalências de 8,9\% e 4,3\% de baixo $(<2500 \mathrm{~g})$ e alto $(>4000 \mathrm{~g})$ peso ao nascer, respectivamente, com média de peso ao nascer de $3160 \pm 540$ gramas, com 6,0\% dos partos prematuros (Monteiro et al., 2000c).

Dados sobre o peso ao nascer no Municipio de São José dos Campos encontram-se disponiveis a partir do ano de 1994 (Ministério da Saúde, 2005), apesar do grande número de informaçðes ignoradas a respeito do peso ao nascer $(48,2 \%$ dos nascidos vivos daquele ano) foram verificadas prevalências de baixo e alto peso ao nascer de $9,8 \%$ e 3,9\%, respectivamente. No ano seguinte (1995), as proporções mantiveram-se semelhantes $(9,2 \%$ de baixo e $3,8 \%$ de alto peso ao nascer), no entanto as informaçð̃es contaram com $99,5 \%$ dos dados sobre os nascidos vivos.

Pode-se considerar que os resultados apresentados, referentes às prevalências de baixo $(7,7 \%)$ e alto $(4,3 \%)$ peso ao nascer, mostraram valores aproximados aos encontrados no Município de São José dos Campos, no ano de 1995. É possível que os achados do presente estudo não representem a distribuição do peso ao nascer de 15 anos atrás neste Município, no entanto, as informaçð̃es disponíveis que mais se aproximam da época em que nasceram os entrevistados referem-se aos anos de 1994 e 1995.

A prevalência de sobrepeso, segundo classificação do IMC, nos indivíduos estudados $(\mathbf{1 4 , 7 \% )}$ mostrou-se ligeiramente superior aos valores identificados por outros autores que analisaram os dados da Pesquisa sobre Padrões de Vida (PPV, 1997), realizada nas regióes Nordeste e Sudeste do Brasil, que encontraram prevalência de sobrepeso em tomo de $12,0 \%$, sendo que em todas as comparaç̋es entre as duas regiơes, a população do Sudeste apresentou maior número de casos de excesso de peso corporal (Wang et al., 2002; Abrantes et al., 2002; Abrantes et al., 2003; Magalhães \& Mendonça, 2003). 
No entanto, os achados do presente estudo aproximaram-se aos encontrados em adolescentes de alto nível sócio-econômico, residentes no Município de Recife, onde $14,4 \%$ do grupo apresentou sobrepeso (Silva et al. 2005).

\subsection{Diagnóstico do estado nutricional atual}

Para a avaliação do estado nutricional durante a adolescência deve-se considerar as modificaçðes na composição corporal referentes aos diferentes estágios de maturaçăo sexual. Sabe-se que individuos pós-púberes apresentam maior conteúdo de massa muscular e de tecido adiposo, quando pertencentes aos sexos masculino e feminino, respectivamente. No entanto, a determinação do estágio de maturação sexual requer identificacão do nível de desenvolvimento dos caracteres sexuais secundários, geralmente obtidos por meio de exame clínico ou por questionários de autoavaliação, associada a informações como ocorrência da menarca em meninas e de voz adulta em meninos (WHO, 1995).

Segundo Duarte (1993), a menarca consiste num marcador importante para o aumento na quantidade de tecido adiposo nas adolescentes brasileiras, enquanto que para o sexo masculino, parece não ocorrer relação entre pregas cutâneas e o processo de maturação sexual.

Recentemente, estudo conduzido no Municipio do Rio de Janeiro, identificou risco aumentado para o desenvolvimento de sobrepeso/ obesidade nos adolescentes de baixo nível sócio-econômico pertencentes aos estágios mais avançados de maturação sexual (Oliveira \& Veiga, 2005).

Devido à dificuldade para identificação dos diferentes estágios de maturação sexual, uma vez que o exame clínico envolve constrangimento entre os entrevistados (Duarte, 1993) e os questionários de auto-avaliação mostram-se pouco precisos devido ao risco de sub ou super-estimação decorrentes de problemas de interpretaçăo, informaçð̃es referentes a menarca e aparição de voz adulta podem ser utilizadas como sinalizadores de que os individuos já experimentaram seu pico 
máximo de velocidade de crescimento e, portanto, encontram-se na fase pós- púbere (WHO, 1995).

Informaçð̃es referentes à população adolescente norte-americana apontam que, em média, o pico máximo de velocidade de crescimento ocorre ao 13,5 e 11,7 anos para os meninos e meninas, respectivamente, e que o desenvolvimento de voz adulta nos meninos acontece por volta dos 14,5 anos, e a menarca, aos 12,8 anos (WHO, 1995).

Em nosso Pais, a maioria dos estudos referentes à menarca contemplou amostras pequenas e não representativas da população adolescente brasileira (Duarte, 1993). Inquérito nutricional realizado em 1989 pelo Ministério da Saúde, juntamente com o Instituto Nacional de Alimentação e Nutrição (INAN) identificou que a idade mediana da menarca correspondia a 13 anos e 2 meses, no entanto, este valor pode estar superestimado, uma vez que meninas com idade inferior a 10 anos não responderam tais questionamentos (INAN, 1990).

No presente estudo, dados referentes à menarca (ocorrência e período) consistem nas únicas variáveis coletadas que permitem categorizar as meninas em pré-púberes e pós-púberes. No entanto, devido à faixa etária contemplada (14 a 23 anos, média de $15,25 \pm 1,4$ anos), pode-se considerar que grande proporção dos meninos e meninas encontram-se na fase pós-púbere, ou seja, já vivenciaram o pico máximo de velocidade de crescimento e desenvolvimento dos caracteres sexuais secundários.

Considerando-se as modificações na composição corporal, tipicas da adolescência e a dificuldade para determinação dos diferentes estágios de maturação sexual, bem como a escassez de estudos representativos que relacionaram indices antropométricos segundo estágios de maturação sexual, pode-se utilizar o IMC para investigação de excesso de peso corporal em grupos de adolescentes, desde que controlado por sexo e idade (WHO, 1995; Fisberg et al., 2004).

Apesar de amplamente utilizado em estudos populacionais, o IMC nð̃o se apresenta como um bom identificador da composição corporal. Aspectos como incremento do 
desenvolvimento muscular, aumento no perímetro cefálico e maior proporção do tronco corporal em relação ao comprimento das pernas, refletem em aumento nos valores de IMC independentemente do conteúdo de gordura corporal. No entanto, tais consideraç̃es mostram-se mais pertinentes em relação à avaliação da composição corporal de crianças menores de 05 anos e não de adolescentes (Roberts \& Dallal, 2001).

Os pontos de corte utilizados para diagnóstico de sobrepeso e obesidade dos entrevistados, recomendados por uma força tarefa internacional que discutiu a questão da obesidade durante a infância e adolescência, consideram as diferenças corporais entre meninos e meninas ao longo do crescimento físico, uma vez que propõem diferentes valores para cada faixa etária e sexo. Além disso, contou com uma amostra internacional, representativa de diversos paises, incluindo o Brasil.

Os pontos de corte propostos por Cole et al. (2000) quando comparados com a nova curva de crescimento da população norte-americana (Kuczmarski et al. 2000), mostram-se muito semelhantes em relação ao diagnóstico de sobrepeso para adolescentes. Entretanto, os pontos de corte que definem obesidade na população norte-americana apresentam-se mais elevados que a curva internacional, fato que deixaria de classificar como obesos muitos indivíduos quando aplicados os pontos de corte norte-americanos (Roberts \& Dallal, 2001).

Por fim, vale ressaltar que segundo os autores da proposta internacional, os pontos de corte referentes ao diagnóstico de obesidade sofreram maior extrapolação estatística, devido à maior variabilidade entre os diferentes bancos de dados internacionais e por este motivo mostram-se menos úteis que os pontos de corte para identificação de sobrepeso (Cole et al. 2000).

Devido a fato do IMC não diferenciar os compartimentos corporais optou-se por realizar a medida da circunferência da cintura, com objetivo de identificar acúmulo excessivo de tecido adiposo na região abdominal. Do mesmo modo como o IMC, a escolha dos pontos de corte considerou o sexo e a faixa etária dos adolescentes. 
Optou-se pela proposta britânica (McCarthy et al., 2001) e nåo norte-americana (Freedman et al., 1999; Fernández et al., 2004) devido à alta prevalência de obesidade na população americana, resultando em valores de circunferência da cintura mais elevados segundo distribuição percentilar e, pelos critérios metodológicos aplicados na construção da curva britânica, considerados mais adequados para suavização dos percentis, uma vez que contemplam aspectos como a mediana e o coeficiente de variação dos dados. Tais critérios foram propostos por Cole (1993), denominados por método LMS, que também foi empregado para a construção das curvas de IMC internacionais (Cole et al., 2000) e norte-americanas (Kuczmarski et al. 2000).

A avaliaçăo da circunferência da cintura em crianças e adolescentes apresenta-se como uma medida antropométrica interessante para investigação de adiposidade abdominal (Maffeis et al., 2001), no entanto tal prática mostra-se pouco explorada. Nos anos 90, a prevalência de excesso de adiposidade abdominal em crianças e adolescentes norte-americanos aumentou cerca de $60 \%$, enquanto que a prevalência de sobrepeso, estimada por meio do IMC, aumentou aproximadamente $50 \%$ neste mesmo periodo (Cook, 2004).

A técnica da impedância bioelétrica consiste em outro método para avaliação da composição corporal pouco explorado durante a adolescência. De um modo geral, a maioria dos estudos utiliza seus resultados apenas como variáveis descritivas (Marreiro et al., 2004; Mika et al., 2005) devido à ausência de pontos de corte para classificação da composição corporal e à escassez de equações específicas para estimativa da quantidade de gordura corporal e de massa magra nesta faixa etária (Leppik et al., 2004).

Além disso, este método apresenta-se pouco preciso para investigação da composição corporal em crianças e adolescentes devido ao crescimento e desenvolvimento dos tecidos durante esta etapa da vida (Sami \& Garófolo, 2002; Oliveira et al., 2004) e aos diferentes niveis de hidratação encontrados segundo faixa etária, uma vez que as equações para a conversão da água corporal em quantidade de 
massa magra consideram um nivel de hidratação constante entre os individuos (Barros Filho, 2001).

Estudos recentes que correlacionaram os resultados obtidos pela bioimpedância (BIA) com os exames de dupla emissão de feixes de raios X (Sun et al., 2005) e com medidas de pregas cutâneas (Arroyo et al., 2004) concluiram que a BIA consiste em uma alternativa interessante para estimar a porcentagem de gordura corporal em individuos adultos que apresentam quantidade de gordura corporal dentro dos padrões aceitáveis. No entanto, os resultados obtidos pela BIA mostraram tendência em superestimar a quantidade de gordura corporal em individuos magros e subestimar os resultados em obesos, portanto os autores sugerem cautela durante a interpretação dos resultados quando aplicados em grupos com extremos de peso corporal (Arroyo et al., 2004; Sun et al., 2005).

\subsection{Estado nutricional ao nascer e atual}

De um modo geral, os achados referentes à relação entre o estado nutricional ao nascer e excesso de peso corporal do grupo como um todo, apontam para ausência de diferença estatisticamente significativa entre as variáveis analisadas, fato que pode ser justificado pelo reduzido poder estatístico do estudo.

Entretanto, os resultados obtidos sugerem que os efeitos do inadequado estado nutricional ao nascer no estado nutricional atual dos alunos comportam-se de modo diferente entre meninos e meninas. Mostrando consistência com os achados de Ericksson et al. (1999) e Monteiro et al. (2004).

Ericksson et al. (1999), estudando adultos finlandeses encontraram que o risco aumentado para o desenvolvimento de doenças cardiovasculares modifica-se segundo estado nutricional ao nascer e sexo. Para as mulheres este achado parece estar mais relacionado ao comprometimento linear, enquanto que para os homens, ao baixo peso ao nascer. 
Monteiro et al. (2004), analisando uma coorte de adolescentes da Região Sul do País, destacaram a necessidade de estratificar todas as análises por sexo, uma vez que verificaram diferenças entre os fatores de risco para o excesso de peso corporal entre meninos e meninas.

Verificou-se diferença estatisticamente significativa entre os meninos pertencentes ao último tercil de índice ponderal e prevalência de sobrepeso $(\mathrm{p}=0,051)$ e excesso de gordura na região abdominal $(p=0,038)$ e, entre os meninos GIG e quantidade de massa muscular $(p=0,009)$. Vale destacar que as associaçðes entre meninos GIG e valores superiores de circunferência da cintura, estatura e peso corporal encontraramse no limiar de significância estatística, assim como para as associaç̃es entre os meninos de baixo IP e valores superiores de estatura, grupo que também apresentou valores superiores de comprimento ao nascer.

Os resultados referentes às meninas, apesar da reduzida significância estatística, mostraram maior prevalência de sobrepeso, obesidade e valores superiores de peso, circunferência da cintura e IMC entre as meninas PIG. Com relação ao IP, encontrou-se associaçăo limitrofe entre valores superiores de quantidade de gordura corporal nas meninas de baixo índice ponderal e valores inferiores de estatura nas meninas de maior IP, gnupo que também apresentou valores inferiores de comprimento ao nascer. Verificou-se associação estatisticamente significativa entre reduzido conteúdo de massa muscular nas meninas de maior IP $(p=0,012)$.

No presente estudo, os índividuos pertencentes ao primeiro tercil de IP caracterizaram-se como bebês assimétricos e magros, uma vez que apresentaram menores valores de peso ao nascer e valores superiores de comprimento ao nascer (Tabela 08), ao passo que os jovens situados no último tercil de IP mostraram menores valores de comprimento e valores elevados de peso ao nascer. Deste modo, pode-se sugerir que os jovens magros ao nascer (baixo IP) sofreram restriçðes nutricionais no final da gestação, periodo em que ocorre a multiplicação dos adipócitos e por este motivo estariam "menos predispostos" ao desenvolvimento de excesso de peso corporal, enquanto que os jovens com comprometimento linear ao 
nascer (alto IP), teriam sofrido restrições nutricionais no início da gestaç̃̃o, período de maior diferenciação e organização dos órgãos vitais, inclusive o hipotálamo e, portanto, apresentariam maior predisposição ao excesso de peso. No entanto, esta relação mostrou-se mais clara para os meninos do que para as meninas.

Analisando-se os jovens segundo peso ao nascer por idade gestacional, verificou-se que os valores médios de comprimento ao nascer elevam-se conforme categorias de peso ao nascer, resultando em maior comprometimento linear entre o grupo PIG (Tabela 14), sendo que esta relação manteve-se entre os sexos (Tabelas 16 e 17). Os achados referentes às meninas PIG, portanto, sugerem consistência com os resultados encontrados por Ericksson et al. (1999).

Os achados do presente estudo sugerem que o comprimento ao nascer parece relacionar-se com a quantidade de massa muscular e estatura no futuro, uma vez que foram identificados valores superiores destas variáveis antropométricas nos grupos com valores elevados de comprimento ao nascer.

Revisão bibliográfica realizada por Pescador et al., (2001) aponta para o fato de que individuos pequenos para idade gestacional apresentam maior predisposição para o desenvolvimento de baixa estatura na idade adulta, aspecto também identificado entre os jovens do presente estudo, verificado com maior intensidade entre os meninos.

Resultados de uma coorte conduzida na Guatemala apontaram para tendência de valores médios inferiores de estatura, peso corporal, quantidade de gordura corporal e massa muscular entre os adolescentes do sexo masculino nascidos com crescimento intra-uterino restrito quando comparados aos garotos adequados para idade gestacional. Para as meninas, os autores encontraram tendência semelhante à descrita para o sexo masculino. Vale destacar que as meninas PIG mostraram tendência em apresentar maior relação entre circunferência da cintura e quadril. No entanto, assim como no presente estudo, tais resultados contaram com uma amostra reduzida ( $\mathrm{n}=$ 331) e não mostraram significância estatística (Martorell et al., 1998). 
Anos depois, ao ingressar na idade adulta (entre 21 e 27 anos), a mesma população sofreu nova reavaliação, indicando que tanto a desnutrição intra-uterina quanto 0 déficit em estatura nos primeiros 02 anos de vida influenciaram a composiçăo corporal destes individuos, resultando em valores finais inferiores de peso corporal e estatura (Li et al., 2003).

Assim como no presente estudo, os resultados de uma coorte de adolescentes residentes na Região Sul do Brasil, mostraram que o alto peso ao nascer (neste estudo representado por valores $\geq 4000 \mathrm{~g}$ ) associou-se positiva e linearmente com sobrepeso e obesidade durante a adolescência, principalmente no sexo masculino (Monteiro et al., 2003b).

Pesquisa realizada com jovens paulistanos de ambos os sexos, com 13,0 $\pm 1,7$ anos de idade, encontrou associação entre excesso de gordura abdominal $(p=0,04)$ e obesidade $(p=0,05)$ no grupo com peso de nascimento acima de $3500 \mathrm{~g}$ (BismarckNasr et al., 2004).

Resultados semelhantes também foram descritos por outros autores, em diversas localidades, sobretudo em nações desenvolvidas, sendo as análises realizadas principalmente com individuos ingressantes no serviço militar (Rasmussen \& Johansson 1998; Seidman et al. 1991).

Na Suécia foi verificada maior predisposiçăo para o desenvolvimento de sobrepeso e obesidade aos 18 anos de idade nos meninos nascidos com alto peso ao nascer, sendo que os autores também identificaram interferência em relação ao comprimento ao nascer, ou seja, tanto individuos nascidos com peso elevado e comprimento adequado para idade gestacional ou com comprimento acima da média para idade gestacional mostraram associaçðes estatisticamente significativas com IMC no momento de ingresso ao serviço militar (Rasmussen \& Johansson, 1998).

Seidman et al. (1991) estudando uma coorte de jovens Israelenses de ambos os sexos, detectaram maiores valores de IMC aos 17 anos naqueles jovens que nasceram com 
peso superior a $3500 \mathrm{~g}$, sendo que o risco para o desenvolvimento de sobrepeso e obesidade aumentou segundo peso ao nascer. Para os jovens com peso de nascimento superior a $4500 \mathrm{~g}$, os autores obtiveram valores de odds ratio estimados em 2,16 para os meninos e 2,95 para as meninas em relação às chances para o desenvolvimento de sobrepeso no grupo analisado, sugerindo que o alto peso ao nascer associa-se fortemente com IMC em jovens adultos.

Outro aspecto interessante refere-se ao fato que, entre os indivíduos com diagnóstico de sobrepeso foram identificadas maiores proporç̋̃es de alunos pertencentes ao grupo PIG $(20,0 \%)$ e GIG $(18,3 \%)$ quando comparados aos AIG $(12,8 \%)$ (Tabela 15). Embora tais resultados não apresentem significância estatística, pode-se sugerir que os indivíduos pertencentes aos extremos de peso ao nascer enquadram-se em uma categoria de risco para o desenvolvimento de sobrepeso e obesidade no futuro, uma vez que, em média, ainda são adolescentes e, apesar dos achados referentes ao excesso de peso corporal mostrarem-se superiores, principalmente entre as meninas PIG e meninos GIG, tais indivíduos não viveram tempo suficiente para a manifestação dos efeitos tardios da programação.

Segundo Kramer (2004), estudos epidemiológicos com objetivo de identificar os efeitos da nutrição no periodo gestacional na gênese de doenças durante a idade adulta devem destinar atenção especial também ao excesso de peso ao nascer, uma vez que esta característica apresenta maior predisposição ao desenvolvimento de obesidade durante a infância $e$ idades posteriores.

\subsection{Limitaçðes do estudo}

$O$ poder estatístico do estudo sofreu influência do pequeno tamanho da amostra que, por sua vez, ficou prejudicada devido a fato de nem todos os alunos possuírem o cartão fornecido pela maternidade, há cerca de 15 anos.

No presente estudo foram considerados apenas dois momentos para verificar a relação entre o estado nutricional ao nascer e atual. Na ausência de uma terceira 
informação antropométrica, intermediária, torna-se dificil distinguir a interferência do peso ao nascer na prevalência de excesso de peso corporal atual. É possível que no periodo compreendido entre o nascimento e a avaliação antropométrica, outros aspectos (atividade física, alimentação) tenham afetado a composição corporal do grupo, uma vez que se trata de um intervalo muito grande de tempo e apenas estas duas informações não contam a trajetória antropométrica destes indivíduos.

Outro aspecto importante a ser considerado seria a avaliação do estado nutricional materno durante a gestação dos indivíduos estudados. Resultados de uma coorte conduzida nas Filipinas sugerem que a desnutrição materna no final do periodo gestacional e sua conseqüente oferta inadequada de nutrientes ao feto parece interferir com maior intensidade na predisposição ao desenvolvimento de doenças cardiovasculares durante a adolescência quando comparada ao peso de nascimento (Kuzawa \& Adair, 2004). Estes autores identificaram perfil lipídico com maior potencial aterogênico (valores inferiores de lipoproteina de alta densidade e superiores de colesterol total e lipoproteina de baixa densidade) entre os adolescentes do sexo masculino que sofreram restriçðes nutricionais no final da gestação.

Além disso, a elevada velocidade de crescimento pós-natal e o tipo de alimentação oferecido durante o periodo neonatal também parecem interferir na predisposição ao desenvolvimento de doenças crônicas no futuro (Stettler et al., 2002; Gunnarsdottir \& Thorsdottir, 2003; Singhal \& Lucas, 2004).

Estudos longitudinais realizados nas Ilhas Seychelles, pais localizado no Oceano Índico e em intenso processo de transição nutricional (Stettler et al., 2002) e na Islândia (Gunnarsdottir \& Thorsdottir, 2003) verificaram que o elevado ganho de peso no primeiro ano de vida associou-se significativamente à prevalência de sobrepeso e obesidade na infância e adolescência.

Um grupo de pesquisadores que analisaram bebes prematuros que receberam fórmulas infantis para pré-termos com àqueles alimentados com leite humano ou fórmulas infantis tradicionais, verificou resultados desfavoráveis em relação ao perfil 
lipídico sanguineo, pressão arterial, resistência à leptina e à insulina durante a infância e adolescência nos bebês que receberam fórmula infantil com maior densidade energética e protéca (fórmula para prematuros) e que, conseqũentemente, apresentaram maior crescimento pós-natal (Singhal et al., 2002; Singhal et al., $2003 b$; Singhal et al., 2004).

Segundo estes autores, devido ao fato de bebês com crescimento intra-uterino restrito mostrarem rápido crescimento pós-natal, as associaç̃es entre baixo peso ao nascer e doenças crônicas no futuro, poderiam sinalizar, na realidade, as consequêencias decorrentes dos efeitos adversos de uma aceleração no crescimento e não de restriçōes nutricionais no periodo gestacional (Singhal \& Lucas, 2004).

Apesar de não contemplar os objetivos do presente estudo, verificou-se entre o grupo com diagnóstico de sobrepeso, maior proporção de individuos que não receberam leite humano (16,7\%), quando comparados aos demais com IMC adequado (10,9\%), no entanto, tal achado não mostrou significância estatistica $(p=0,431)$.

Segundo Gillman (2002), parecem existir três possiveis inferências a partir de estudos que analisaram o aumento no risco para o desenvolvimento de doenças cardiovasculares tanto em individuos que nasceram pequenos para idade gestacional quanto naqueles que adquiriram excesso de peso corporal no decorrer da vida $\mathbf{A}$ primeira refere-se ao aumento no risco para o desenvolvimento de doenças crônicas no futuro devido a um rápido crescimento pós-natal. A segunda inferência aponta para os riscos oriundos de um crescimento intra-uterino restrito e, a terceira representa uma interaçăo entre as duas primeiras inferências. Por este motivo, o autor sugere que estudos sobre $a$ origem fetal de doenças contemplem diversas avaliaçōes antropométricas ao longo da infância, adolescência e vida adulta, permitindo a diferenciaçăo entre influências pré-natais e decorrentes de um rápido crescimento em periodos críticos para o desenvolvimento da obesidade.

Estudos epidemiológicos e experimentais sugerem fortes evidèncias de que os efeitos da programação interferem na gênese de doenças na idade adulta, sendo este fato 
particularmente importante em nações que experimentam o processo de transição nutricional. Por este motivo, as políticas de saúde pública devem intensificar seus esforços em medidas que promovam adequado ganho de peso intra-uterino e nutrição pós-natal, estimulando a prática de aleitamento materno. Evitando, deste modo, dilemas como promover ou não a rápida recuperação do estado nutricional durante a infância, principalmente com intervençðes nutricionais que proporcionem maior ganho de peso corporal do que de estatura, refletindo em aumento de gordura corporal, como antigos programas de alimentação e nutrição que preconizavam a distribuição de alimentos para enriquecimento do valor calórico da dieta oferecida ao público infantil (Victora \& Barros, 2001). 
7. CONCLUSÕES E RECOMENDAÇÕES 
Apesar do reduzido poder estatistico do estudo, pode-se sugerir que os individuos pertencentes aos extremos de peso ao nascer segundo idade gestacional e de índice ponderal, enquadram-se em uma categoria de risco para o desenvolvimento de excesso de peso corporal no futuro, sendo que esta relação mostrou-se mais evidente para o sexo masculino.

Os achados do presente estudo sinalizam que, conforme o sexo do individuo, o inadequado estado nutricional ao nascer pode acarretar em maior predisposição para o desenvolvimento de excesso de peso corporal no futuro, principalmente entre os meninos GIG e com alto índice ponderal e meninas PIG e com baixo índice ponderal.

Por este motivo, investigaç̃es epidemiológicas referentes aos efeitos tardios da programạ̧ao devem estratificar suas análises segundo sexo. Assim como, também seria interessante investigar o modo no qual o comprimento ao nascer reflete na composição corporal futura dos indivíduos, uma vez que foram identificados valores superiores de quantidade de massa muscular e estatura na juventude nos grupos com valores elevados de comprimento ao nascer.

É possível que os efeitos tardios da programação, sobretudo àqueles referentes aos objetivos do presente estudo, ainda não se manifestaram completamente nos indivíduos em questão, devido à idade ainda precoce. Tratando-se de um assunto anda pouco explorado, recomenda-se que para futuras investigą̧ðes, considerem-se estudos com delineamento longitudinal, permitindo o aprimoramento da acurácia das informações referentes à alimentação nos primeiros anos de vida e a inclusão de avaliaç̃es antropométricas intermediárias, com objetivo de identificar a trajetória nutricional destes indivíduos. 
8. REFERÊNCLAS BIBLIOGRÁFICAS 
Abrantes, MM; Lamounier, JA; Colosimo, EA. Prevalência de sobrepeso e obesidade em crianças e adolescentes das regióes Sudeste e Nordeste. J Pediatr 2002; 78 (4): 335-340

Abrantes, MM; Lamounier, JA; Colosimo, EA. Prevalência de sobrepeso e obesidade nas regiōes nordeste e sudeste do Brasil. Rev Assoc Med Bras 2003; 49 (2): 162166.

Adair, LS. Earty nutrition conditions and later risk of disease. In: Caballero, B \& Popkin, BM. The nutrition transition: diet and disease in the developing world. London, Academic Press, 2002.

Allen, L \& Gillespie, S. What works? A review of the efficacy and effectiveness of nutrition interventions. United Nations Administrative Committee on Coordination/ sub-Committee on Nutrition- ACC/ SCN in collaboration with the Asian Development Bank, Manila. Geneva, 2001.

Arroyo, M; Rocandio, AM; Ansotegui, L; Herrera, H; Salces, I; Rebato, E. Comparison of predicted body fat percentage from anthropometric methods and from impedance in university students. Br J Nutr 2004; 92: 827-832.

Barker, DJP; Eriksson, JG; Forsén, T; Osmond, C. Fetal origins of adult disease: strength of effects and biological basis. Int J Epidemiol 2002; 31: 1235-1239.

Barker, M; Robinson, S; Osmond, C; Barker, DJP. Birth weight and body fat distribution in adolescent girls. Arch Dis Child 1997; 77: 381-383.

Barros Filho, AA. Métodos de avaliação da composição corporal em crianças. In: Barbieri, D \& Palma, D. Gastroenterologia e nutrição. Série Atualizações Pediátricas. São Paulo, Ed Atheneu, 2001. 
Beall,MH; Haddad, M; Gayle, D; Desai, M; Ross, MG. Adult obesity as a consequence of in utero programming. Clinical Obstetrics and Gynecology 2004; 47 (04): 957-966.

Bénéfice, E; Garnier, D; Simondon, KB; Malina, RM. Relationship between stunting in infancy and growth and fat distribution during adolescence in Senegalese girls. Eur J Clin Nutr 2001; 55: 50-58.

Ben-Shlomo, Y \& Kuh, D. A life course approach to chronic disease epidemiology: conceptual models, empirical challenges and interdisciplinary perspectives. Int $\mathbf{J}$ Epidemiol 2002; 31 : 285-293.

Bismarck-Nasr, EM; Frutuoso, MFP; Gambardella, AMD. Relação entre peso a nascer e adiposidade em adolescentes. In: VI Congresso Brasileiro de Epidemiologia. Recife, 19 a 22 de Junho de 2004.

Bouchard, C. Obesity in adulthood- the importance of chilhood and parental obesity. N Engl Med 1997; 73 (13): 926-927.

Clarke, WR \& Lauer, RM. Does childhood obesity track into adulthood? Crit Rev Food Nutr 1993; 33 (4/5): 423-430.

Cole, TJ. The use and construction of anthropometric growth reference standards. Nutrition Research Reviews 1993; 06: 19-50.

Cole, TJ; Bellizi, MC; Flegal, KM; Dietz, WH. Establishing a standard definition for child overweight and obesity worldwide: international survey. BMJ 2000; 320: 1240-1243.

Cook, S. The metabolic syndrome: antecedent of adult cardiovascular disease in pediatrics. The Journal of Pediatrics 2004; 145: 427-430. 
Daniels, SR; Khoury, PR; Morrison, JA. Utility of different measures of body fat distribution in children and adolescents. Am J Epidemiol 2000; 152: 1179-1184.

Dean, AG; Dean, JA; Coloumbier, D; Burton, AH; Brendei, KA; Smith, DC. Epi Info, version 6.04: a word processing, database, and statistics program for public health on microcomputers. Genebra: Centers for Disease Control and Prevention/ World Health Organization; 1996. URL:

Dietz, W.H. Critical periods in childhood for the development of obesity. Am J Clin Nutr 1994; 59: 955-959.

Dietz, WH. Periods of risk in childhood for the development of adult obesity. What do we need to learn? J Nutr 1997; $127: 1884 S-1886 S$.

Dietz, W.H. Health consequences of obesity in youth: childhood predictors of adult disease. Pediatrics. 1998a; 101: 518-525.

Dietz, W.H. Childhood weight affects adult morbidity and mortality. J Nutr 1998b; 128: $411 \mathrm{~s}-414 \mathrm{~s}$.

Duarte, MFS. Maturaçăo física: uma revisão da literatura, com especial atenção à criança brasileira Cad Saúde Públ 1993; 09 (supl.01): 71-84.

Egger, G \& Swinburn, B. An "ecological" approach to the obesity pandemic. BMJ $1997 ; 315: 477-480$.

Eriksson, JG; Forsén, T; Tuomilehto, J; Winter, PD; Osmond, C; Barker, DJP. Catch- up growth in childhood and death from coronary heart disease: longitudinal study. BMJ 1999; 318: 427-431.

Fernández, JR; Redden, DT; Pietrobelli, A; Allison, DB. Waist circumference percentiles in nationally representative samples of african-american, european- 
american, and mexican-american children and adolescents. J Pediatr 2004; 145 : 439-444.

Fletcher, MA. Physical assessment and classification. In: Avery, GB; Fletcher, MA; MacDonald, MG. Neonatology - Pathophysiology and management of the newborn. $4^{2}$ ed. Philadelphia: JB Lippincott, pp. 269-288, 1994.

Forsén, T; Eriksson, JG; Tuomilehto, J; Osmond, C; Barker, DJP. Growth in utero and during childhood among women who develop coronary heart disease: longitudinal study. BMJ 1999; 319: 1403-1407.

Foster, KR \& Lukaski, HC. Whole-body impedance - what does it measure? Am J Clin Nutr 1996; 64: (suppl): 388S-396S.

Fisberg, M; Baur, L; Chen, W; Hoppin, A; Koletzko, B; Luau, D; Moreno, L; Nelson, T; Strauss, R; Uauy, R. Obesity in children and adolescents: working group report of the second World Congress of Pediatric Gastroenterology, Hepatology, and Nutrition. J Pediatr Gastroenterol Nutr 2004; 39: S678-S687.

Freedman, DS; Serdula, MK; Srinivasan, SR; Berenson, GS. Relation of circumferences and skinfold thicknesses to lipid and insulin concentrations in children and adolescents: the Bogalusa Heart Study. Am J Clin Nutr 1999; 69: 308317.

Frisancho, AR. Prenatal compared with parental origins of adolescent fatness. Am J Clin Nutr 2000; 72: 1186-1190.

Frisancho, AR. Reduced rate of fat oxidation: a metabolic pathway to obesity in the developing nations. Am J Hum Biol 2003; 15: 522-532. 
Frutuoso; MFP. Fatores associados ao sobrepeso e obesidade de individuos de 8 a 18 anos de idade. [doutorado]. Sð̃o Paulo: Faculdade de Saúde Pública, Universidade de Såo Paulo; 2003.

Fundação SEADE. Município de Sx̃o José dos Campos. Disponível em <URL: $>$ [2005 jul 25].

Gillman, MW. Epidemiological challenges in studying the fetal origins of adult chronic disease. Int J Epidemiology 2002; 31: 294-299.

Godfrey, KM \& Barker, DJP. Fetal nutrition and adult disease. Am J Clin Nutr 2000; 71 (suppl): 1344S-1352S.

Gordon, CC; Chumlea, WC; Roche AF. Stature, recumbent lenght, and weight. In: Lohman, TG; Roche, AF; Martorell, R. Anthropometric standardization reference manual. Champaign: Human Kinetics Books; 1988. p. 3-8.

Gunnarsdottir, I \& Thorsdottir, I. Relationship between growth and feeding in infancy and body mass index at the age of 6 years. Int $J$ Obesity 2003; 27: 15231527.

Hediger, ML; Overpeck, MD; Kuczmarski, RJ; McGlynn, A; Maurer, KR; Davis, W. Muscularity and fatness of infants and young children born small- or large- for$\begin{array}{llllll}\text { gestational- } & \text { age. } & \text { Pediatrics } 1998 ; & \text { (5). } & \text { URL: }\end{array}$

Himes, JH \& Diet々, WH. Guidelines for overweight in adolescent preventive services: recommendation from an expert committee. Am J Clin Nutr 1994; 59 : 307-316.

Hoffman, DJ; Sawaya, AL; Verreschi, I; Tucker, KL; Roberts, SB. Why are nutritionally stunted children at increased risk of obesity? Studies of metabolic rate 
and fat oxidation in shantytown children from Sæo Paulo, Brazil. Am J Clin Nutr 2000; 72: 702-707.

Houtkooper, LB; Lohman, TG; Going, SB; Howell, WH. Why bioelectrical impedance analysis should be used for estimating adiposity? Am J Clin Nutr 1996; 64 (suppl): $436 S-448 S$.

Iliadou, A; Cnattingius, S; Lichtenstein, P. Low birth weight and type 2 diabetes: a study on 11162 swedish twins. Int J Epidemiol 2004; 33: 948-953.

INAN - Instituto Nacional de Alimentação e Nutrição. Perfil de crescimento da populaçăo brasileira de 0 a 25 anos. Pesquisa Nacional sobre Saúde e Nutriçăo. Brasília, Ministério da Saúde, 1990.

Kramer, MS. Determinants of low birth weight: methodological assessment and meta- analysis. Bull World Health Organ 1987; 65: 663-737.

Kramer, MS; Olivier, M; McLean, FH; Dougherty, GE; Willis, DM; Usher, RH. Determinants of fetal growth and body proportionality. Pediatrics 1990; 86: 18-26.

Kramer, MS. The epidemiology of adverse pregnancy outcomes: an overview. J Nutr 2003; 133: 1592S-1596S.

Kramer, MS. Commentary: matemal nutrition, body proportions at birth, and adult chronic disease. Int J Epidemiology 2004; 33: 837-838.

Kuczmarski, RJ; Ogden, CL; Grummer-Strawn, LM et al. Advance data from vital and health statistics. Hyattsville, MD: National Center for Health Statistics, 2000; 314 (314): 1-28. Disponivel em <URL: http://www.cdc.gov/growthcharts 
Kuzawa, CW \& Adair, LS. A supply-demand model of fetal energy sufficiency predicts lipid profiles in male but not female filipino adolescents. Eur J Clin Nutr 2004; 58: 438-448.

Law, CM; Barker, DP; Osmond, C; Fall, CHD; Simmonds, SJ. Early growth and abdominal fatness in adult life. J Epidemiol Community Health 1992; 46: 184-186.

Law, C. Adult obesity and growth in childhood. BMJ 2001; 323: 1320-1321.

Leppik, A; Jürimăe, T; Jürimăe, J. Influence of anthropometric parameters on the body composition measured by bioelectrical impedance analysis or DXA in children. Acta Paediatr 2004; 93: 1036-1041.

Li, H; Stein, AD; Barnhart, HX; Ramakrishnan, U; Martorell, R. Associations between prenatal and postnatal growth and adult body size and composition. Am J Clin Nutr 2003; 77 : 1498-1505.

Lohman, TG; Roche, AF; Martorell, R. Anthropometric standardization reference manual. Champaign: Human Kinetics Books; 1988.

Loos, RJF; Beunem, G; Fagard, R; Derom, C; Vlietinck, R. Birth weight and body composition in young women: a prospective twin study. Am J Clin Nutr 2002; 75: 676-682.

Lucas, A; Fewtrell, MS; Cole, TJ. Fetal origins of adult disease - the hypotesis revisited. BMJ 1999; 319: 245-249.

Lucas, A. Role of nutritional programming in determining adult morbidity. Arch Dis Child 1994; 71: 288-290.

Lukaski, HC. Methods for the assessment of human body composition: traditional and new. Am J Clin Nutr 1987; 46: 537-556. 
Maffeis, C; Grezzani, A; Pietrobelli, A; Provera, S; Tatò, L. Does waist circumference predict fat gain in children? Intermational Journal of Obesity 2001; 25: $978-983$.

Magalhães, VC \& Mendonça, GAS. Prevalência e fatores associados a sobrepeso e obesidade em adolescentes de 15 a 19 anos das regiðes Nordeste e Sudeste do Brasil, 1996 a 1997. Cad Saúde Pública 2003; 19 (Sup. 1): S129-S139.

Marreiro, DN; Fisberg, M; Cozzolino, SMF. Zinc nutritional status and its relationships with hyperinsulinemia in obese children and adolescents. Biological Trace Element Research 2004; 100:137-149.

Martins, PA. Estudo prospectivo do estado nutricional e composição corporal de crianças desnutridas moradoras de favelas do Município de São Paulo. [mestrado]. São Paulo: Universidade Federal de São Paulo; 2003.

Martorell, R. Obesity in the developing world. In: Caballero, B \& Popkin, BM. The nutrition transition: diet and disease in the developing world. London: Academic Press; 2002.

Martorell, R; Ramakrishnan, U; Schroeder, DG; Melgar, P; Neufeld, L. Intrauterine growth retardation, body size, body composition and physical performance in adolescence. Eur J Clin Nutr 1998; 52:S1, S43-S53.

Martorell, R; Stein, AD; Schroeder, DG. Early nutrition and later adiposity. J Nutr 2001; 131 : 874S-880S.

McCarthy, HD; Jarrett, KV; Crawley, HF. The development of waist circumference percentiles in British children aged 5.0- 16.9y. Eur J Clin Nutr 2001; 55: 902-907.

Ministério da Saúde. Datasus; 2005. Disponível em <URL: http://www.saude.gov.br $>$ [2005 mar 26]. 
Mika, C; Herpertz-Dahlmann, B; Heer, M; Holtkamp, K. Improvement of nutritional status as assessed by multifrequency BIA during 15 weeks of refeeding in adolescent girls with anorexia nervosa. J Nutr 2004; 134: 3026-3030.

Monteiro, CA. Evolução da nutrição infantil nos anos 90. In: Monteiro, CA. Velhos e novos males da saúde no Brasil. São Paulo, Ed Hucitec; 2000.

Monteiro, CA; Mondini, L; Souza, ALM; Popkin, BM. Da desnutriçăo para a obesidade: a transição nutricional no Brasil. In: Monteiro, CA. Velhos e novos males da saúde no Brasil. São Paulo, Ed Hucitec; 2000a.

Monteiro, CA; Benício, MHD'A; Conde, WL; Popkin, BM. Shifting obesity trends in Brazil. Eur J Clin Nutr 2000b; 54: 342-346.

Monteiro, CA; Benício, MHA; Ortiz, LP. Tendência secular do peso ao nascer na cidade de São Paulo (1976-1998). Rev Saúde Pública 2000c; 34 (6 supl): 26-40.

Monteiro, CA \& Conde, WL. A tendência secular da obesidade segundo estratos sociais: Nordeste e Sudeste do Brasil, 1975-1989-1997. Arq Bras Endocrinol Metab 1999; 43: 186-194.

Monteiro, CA \& Conde, WL. Evolução da obesidade nos anos 90: a trajetória da enfermidade segundo estratos sociais no nordeste e sudeste do Brasil. In: Monteiro, CA. Velhos e novos males da saúde no Brasil. Såo Paulo, Ed Hucitec; 2000 .

Monteiro, CA; Conde, WL; de Castro, IRR. A tendência cambiante da relação entre escolaridade e risco de obesidade no Brasil (1975-1997). Cademos de Saúde Pública 2003a; 19 (supl 1): S67-S75. 
Monteiro, POA; Victora, CG; Barros, FC; Monteiro, LMA. Birth size, early childhood growth, and adolescent obesity in a Brazilian birth cohort. Int $\mathbf{J}$ Obesity 2003b; 27 : 1274-1282.

Monteiro, P; Victora, C; Barros, F. Fatores de risco sociais, familiares e comportamentais para obesidade em adolescentes. Rev Panam Salud Publica 2004; $16(4): 250-258$.

Must, A; Dallal, GE; Dietz, WH. Reference data for obesity: $85^{\text {th }}$ and $95^{\text {th }}$ percentiles of body mass index (wt/ht ${ }^{2}$ ) and triceps skinfold thickness. Am J Clin Nutr 1991; 53: 839-846.

Must, A.; Jacques, P.F.; Dallal, G.E.; Bajema, C.J.; Dietz, W.H. Long-term morbidity and mortality of overweight adolescents. A follow-up of the Haward Growth Study of 1922 to 1935. N Engl J Med 1992; 327 (19): 1350-1355.

Oliveira, FLC; Sami, RS; Taddei, JAAC. Avaliagãa da condiçāo nutricional do paciente hospitalizado. In: Cardoso, AL; Lopes, LA; Taddei, JAAC. Tópicos atuais em nutriçăo pediátrica. Såo Paulo, Ed Atheneu, 2004.

Oliveira, CS \& Veiga, GV. Estado nutricional e maturação sexual de adolescentes de uma escola pública e de uma privada no Municipio do Rio de Janeiro. Rev Nutr 2005 ; 18 (02): 183-191.

Parsons, TJ; Power, C; Manor, O. Fetal and early life growth and body mass index from birth to early adulthood in 1958 British cohort: longitudinal study. BMJ 2001; 323: 1331-1335.

Pescador, MVB; Streher, AAF; Silva JMF; Valente, GCC; Nakagiri, M; Boguszewski, MCS. Aspectos endocrinológicos das crianças e adultos nascidos pequenos para idade gestacional. Arq Bras Endocrinol Metab 2001; 45 (01): 15-23. 
Pietiläinen, KH; Kaprio, J; Răsănen, M; Rissanen, A; Rose, RJ. Genetic and environmental influences on the tracking of body size from birth to early adulthood. Obesity Research 2002; 10: 875-884.

Pietiläinen, KH; Kaprio, J; Răsånen, M; Winter, T; Rissanen, A; Rose, RJ. Tracking of body size from birth to late adolescence: contributions of birth length, birth weight, duration of gestation, parents' body size, and twinship. Am J Epidemiol $2001 ; 154: 21-29$.

Popkin, BM. An overview on the nutrition transition and its health implications: the Bellagio meeting. Public Health Nutr 2002; 5(1 A): 93-103.

Popkin, BM \& Doak, CM. The obesity epidemic is a worldwide phenomenon. Nutr Rev 1998; 56: 106-114.

Rasmussen, F \& Johansson, $M$. The relation of weight, length and ponderal index at birth to body mass index and overweight among 18-year-old males in Sweden. Eur J Epidemiol 1998; 14: 373-380.

Ravelli, ACJ; Meulen, JHPD; Osmond, C; Barker, DJP; Bleker, OP. Obesity at the age of $50 \mathrm{y}$ in men and women exposed to famine prenatally. Am J Clin Nutr 1999; 70: $811-816$.

Ravelli, GP; Stein, Z; Susser, M. obesity in young men after famine exposure in utero and early infancy. N Engl J Med 1976; 259: 349-353.

RJL Systems. Bioelectrical Impedance Analysis [on line]. Disponivel em <URL:http://www.rjlsystems.com/research.html. [27 out 2000]

Roberts, SB \& Dallal, GE. The new childhood growth charts. Nutrition Reviews $2001 ; 59(02): 31-36$ 
Robinson, R. The fetal origins of adult disease. BMJ 2001; 322: 375-376.

Sami, RS \& Garófolo, A. Métodos empregados na avaliação da composição corporal. In: Lopez, FA; Sigulem, DM; Taddei, JAAC. Fundamentos da terapia nutricional em pediatria. São Paulo, Ed Sarvier, 2002.

Schneider, D. International trends in adolescent nutrition. Soc Sci Med 2000; 51 : 955-967.

Secretaria Municipal de Saúde. Município de São José dos Campos. Epidemiologia; 2004. Disponível em <URL: http://www.sjc.sp.gov.br> [2005 mar 21].

Seidman, DS; Laor, A; Gale, R; Stevenson, DK; Danon, YL. A longitudinal study of birth weight and being overweight in late adolescence. Am J Dis Child 1991, 145: 782-785.

Sichieri, R \& Allam, VLC. Avaliação do estado nutricional de adolescentes brasileiros através do indice de massa corporal. J Ped 1996; 72: 80-84.

Silva, GAP; Balaban, G; Motta, MEFA. Prevalência de sobrepeso e obesidade em crianças e adolescentes de diferentes condiçőes socioeconômicas. Rev Bras Saúde Matern Infant 2005; 5 (01): 53-59.

Singhal, A; Cole, TJ; Fewtrell, M; Lucas, A. Breast- milk feeding and the lipoprotein profile in adolescents born preterm. Lancet 2004; 363: 1571-1578.

Singhal, A \& Lucas, A. Early origins of cardiovascular disease: is there a unifying hypothesis? Lancet 2004; 363: 1642-1645.

Singhal, A; Sadaf-Farooqi, I; O'Rahilly, S; Fewtrell, M; Lucas, A. Early nutrition and leptin concentrations in later life. Am J Clin Nutr 2002; 75: 993-999. 
Singhal, A; Fewtrell, M; Cole, TJ; Lucas, A. Low nutrient intake and early growth for later insulin resistance in adolescents born preterm. Lancet 2003b; 361: 1089 1097.

Singhal, A; Wells, J; Cole, TJ; Fewtrell, M; Lucas, A. Programming of lean body mass: a link between birth weight, obesity, and cardiovascular disease. Am J Clin Nutr 2003a; 77: 726-730.

Stettler, N; Bovet, P; Shamlaye, H; Zemel, BS; Stallings, VA; Paccaud, F. Prevalence and risk factors for overweight and obesity in children from Seychelles, a country in rapid transition: the importance of early growth. Int $\mathbf{J}$ Obesity 2002; 26: 214-219.

Sun, G; French, CR; Martin, GR; Younghusband, B; Green, RC; Xie, Y; Mathews, M. Barron, JR; Fitzpatrick, DG; Gulliver, W; Zhang, H. Comparison of multifrequency biolectrical impedance analysis with dual- energy X-ray absorptiometry for assessment of percentage body fat in a large, healthy population. Am J Clin Nutr 2005; 81 : 74-78.

Taylor, RW; Jones, IE; Williams, SM; Goulding, A. evaluation of waist circumference, waist - to -hip ratio, and the conicity index as screening tools for high trunk fat mass, as measured by dual -energy $\mathbf{X}$-ray absorptiometry, in children aged 3-19y. Am J Clin Nutr 2000; 72: 490-495.

Troiano, R.P.; Flegal, K.M.; Kuczmarski, R.J.; Campell, S.M.; Johnson, C.L. Overweight prevalence and trends for children and adolescents. Arch Pediatr Adolesc Med 1995; 149: 1085-1091.

UNICEF. Situạ̧ão mundial da infância 1998. Brasília: UNICEF, 1998. 
Vanhala, M; Vanhala, P; Kumpusalo, E; Halonen, P; Takala, J. relation between obesity from childhood to adulthood and the metabolic syndrome: population based study. BMJ 1998; 317: 319.

Victora, CG \& Barros, FC. Commentary: the catch- up dilemma - relevance of Leitch's 'low-high' pig to child growth in developing countries. Int J Epidemiology 2001; 30: 217-220.

Walker, SP; Gaskin, PS; Powell, CA; Bennett, FI. The effects of birth weight and postnatal linear retardation on body mass index, fatness and fat distribution in mid and late childhood. Public Health Nutr 2002; 5 (3): 391-396.

Wang, Y; Monteiro, CA; Popkin, BM. Trends of obesity and underweight in older children and adolescents in the United States, Brazil, China and Rússia Am J Clin Nutr 2002; 75: 971-977.

Weyer, C; Patley, RE; Lindsay, RS; Tartaranni, PA. relationship between birth weight and body composition, energy metabolism, and sympathetic nervous system activity later in life. Obes Res 2000; 8: 559-565.

Whitaker, RC \& Dietz, WH. Role of the prenatal environment in the development of obesity. J Pediatr 1998; 132: 768-776.

Williams, RL et al. Fetal growth and perinatal viability in California Obstetrics and gynecology; 1982, 59: 624-632.

World Health Organization (WHO). Physical status: the use and interpretation of anthropometry. Geneva, 1995.

World Health Organization (WHO). Obesity: preventing and managing the global epidemic. Geneva, 2000. 


\section{Pesquisa: Relaça entre as condipöes nutricionais ao nascer e compasicilo corporal de adalescentes e jovens adultos}

\section{DENTIFICAÇÃO}

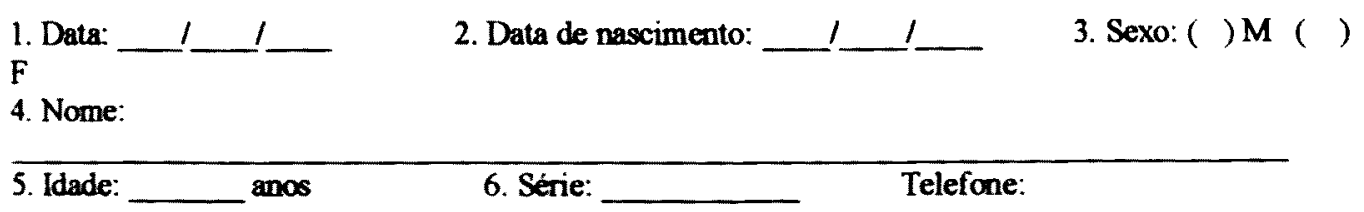

6. Há quanto tempo você freqùenta este colégio?

7. Você tem algum problema de saúde (bronquite, asma, etc)? ( ) sim ( ) não 8. Se sim, qual? Desde qual idade?

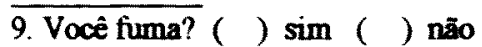
10. Quantos cigarros/ dia?

11. Você costuma tomar alguma bebida aloóolica? ( ) sim ( ) não

12. Se sim, qual (is)?

13. Quantas vezes por semana? 14. Quantas doses/ dia?

\section{ATIVIDADE FISICA}

\section{Você assiste à televisåo? ( ) Sim ( ) Nåo}

16. Quantas horas/dia?

17. Quantos dias/semana?

\section{Você joga vídeo game? ( ) Sim ( ) Nåo}

19. Quantas horas/dia?

20. Quantos dias/semana?
21. Você utiliza o computador?
22. Quantas horas/dia?
( ) $\operatorname{Sim}() \mathrm{NaO}$

24. O que você faz nos fins de semana?

25 . A que horas você dơrme? $\quad 26$. A que horas você
acorda?

27. Você participa das aulas de Educąåa Física? ( ) sim ( ) não

28. Vocé pratica algum esporte (além das aulas de Educação Física)? ( ) Sim ( ) Não

29. Qual

(is)?

30. Há quanto tempo?

31. Quantas horas/dia?

32. Quantas dias/semana? 
ANEXO I 


\section{Pesquisa: Relasib entre es condipies nutricionais ao nescer e composiplo corponal de adolaceantas e jovens adultes}

\section{DENTIFICAC̄̃̃O}
1. Data:
2. Data de nascimento:
3. Sexo: ( ) M ( )
$\mathrm{F}$
4. Nome:

5. Idade: anos

6. Śrie:

Telefone:

6. Há quanto tempo você frequienta este colégio?

7. Você tem algum problema de saúde (bronquite, asma, etc)?（） sim （）não

8. Se sim, qual? Desde qual idade?
9. Você fưma? ( ) sim ( ) não
10. Quantos cigarros/ dia?

11. Você costuma tomar alguma bebida alcóolica? ( ) sim ( ) não

12. Se sim, qual (is)?

13. Quantas vezes por semana?

14. Quantas doses/

dia?

\section{ATIVIDADE FISICA}

\section{Você assiste à televisăo? ( ) Sim ( ) Năo}

16. Quantas horas/dia?

17. Quantos dias/semana?

18. Você joga vídeo game? ( ) Sim ( ) N̋̋o

19. Quantas horas/dia?

20. Quantos dias/semana?
21. Você utiliza o computador?
( ) Sim ( ) Nho

22. Ouantas horas/dia?

23. Quantos dias/semana?

24. O que vocé faz nos fins de semana?

25. A que horas você dorme?

26. A que horas você acorda?

27. Você participa das aulas de Educacão Física? ( ) sim ( ) não

28. Você pratica algum esporte (além das aulas de Educaçăo Física)? ( ) Sim ( ) Não

29. Qual

(is)?

30. Há quanto tempo?

31. Quantas horas/dia? 32. Quantas dias/semana? 


\section{DADOS ANTROPOMÉTRICOS}

\begin{tabular}{|c|l|l|l|l|l|}
\hline Medida & Estatura & $\begin{array}{c}\text { Circunferência } \\
\text { da cintura }\end{array}$ & Altura sentada & Resistència & Reactância \\
\hline 1 & & & & & \\
\hline 2 & & & & & \\
\hline 3 & & & & & \\
\hline
\end{tabular}

33. Peso atual:

35. Comprimento ao nascer: semanas

37. Perímetro Cefálico:
34. Peso ao nascer:

36. Idade gestacional

38. Petímetro toráxico:

\section{ESCOLARIDADE DOS PAIS}

39. Escolaridade do Pai: ( ) $1^{\circ}$. Grau incompleto ( ) $1^{\circ}$. Grau completo ( ) $2^{\circ}$. Grau incompleto ( ) $2^{\circ}$. Grau completo ( ) Superior incompleto ( ) Superior Completo ( ) Pós-Graduaçăo 40. Profissão do

Pai:

41. Escolaridade da Mãe: ( ) $1^{\circ}$. Grau incompleto ( ) $1^{\circ}$. Grau completo ( ) $2^{\circ}$. Grau incompleto ( ) $2^{\circ}$. Grau completo ( ) Superior incompleto ( ) Superior Completo ( ) Pós-Graduaçåo 42. Profissão

\section{APENAS PARA AS MENINAS}

43. Você já teve a primeira menstruação? （） Sim （）Não 44. Se sim, com que idade? anos. 
ANEXO II 
*Escolha bem o tipo de exercício físico que você vai praticar: associe exercícios aeróbicos (corrida, caminhada, natação, bicicleta, futebol, basquete, vôlei, etc) com exercicios localizados (abdominais, flexão de braço, exercícios de agachamento e levantamento de pesos leves/ caneleiras para os braços e pernas, etc).

- Cuidado com a intensidade dos exercícios localizados: musculação para quem ainda não cresceu "tudo o que tem direito" pode atrapalhar o crescimento!

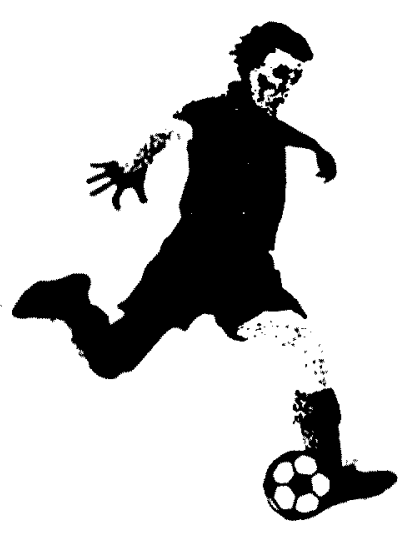

\section{COMO POSSO GANHAR PESO \\ DE FORMA SAUDÁVEL?}

O resultado da sua avaliação física indicou que você está muito magrinho. Este folheto contém algumas dicas para você ganhar peso com saúde.

A adolescência é um dos periodos de maior crescimento corporal, por isso é importante que você atinja o peso ideal para sua idade. para não prejudicar o seu crescimento.

*Procure consumir 6 refeições por dia: café da manhã, lanche da manhã, almoço, lanche da tarde, jantar e lanche da noite. Mas escolha bem os alimentos, caso contrário. você ganhará peso às custas de aumento de tecido adiposo (gordura), que não é legal...
Elizabeth Mario Bismarck Nasr Nutricionista - CRN 12853 Junho/2004 
*Evite consumir tudo aquilo que você já sabe que não é saudável: lanches em fast foods. solgadinhos, refrigerantes, frituras, chocolates, etc.

*Escolha alimentos adequados para cada refeição:

- café da manhã: leite (ou iogurte) com pão ou bolo simples ou biscoitos sem recheio.

- lanche da manha: fruta com uma fatia de pão de forma ou $\frac{1}{2}$ pão francês, caso queira comprar um salgado na cantina, dê preferência aos assados e não fritos. Fuja das massas folhadas!

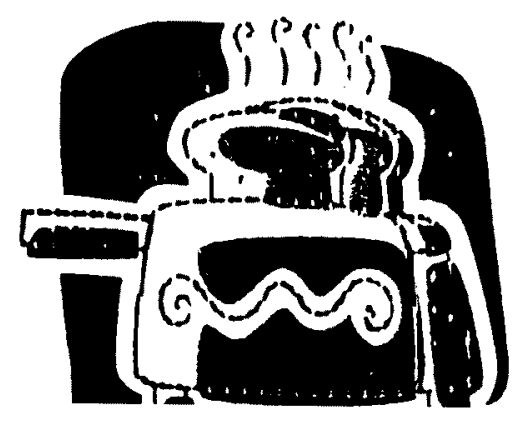

- almaco: arroz + feijão + carnes + salada/ legumes. Evite o consumo excessivo de liquidos junto das refeições. Prefira as frutas e não doces como sobremeso.

- lanche da tarde: leite (ou iogurte) com pão ou bolo simples ou biscoitos sem recheio.

- jantar: igual ao almoço. Os sanduiches podem até substituir as refeições, desde que não se tornem uma substituição freqüente $e$ sejam preparadas com alimentos saudáveis e sem muita gordura. Evite alimentos como maionese, bacon, etc. Para acompanhar 0 sanduiche, escolha sempre um suco de frutas:

- lanche da noite: 1 copo de leite ou iogurte, se sentir vontade, pode completar 0 lanche com frutas.
* Para ganhar peso de forma saudável é preciso associar uma alimentação adequada com exercícios físicos, assim você vai ganhar massa muscular e não tecido gorduroso.

*Antes de praticar exercícios físicos procure fazer um lanche rápido $\$ 45$ minutos antes). Você pode consumir uma banana ou qualquer outra fruta (pode acrescentar me! e/ ou aveia se quiser) ou mesmo consumir uma barrinha de cereais ou um pedaço de bolo simples ou um pão francês...

O importante é não ficar sem comer nada, assim o seu corpo utilizará este lanche para fornecer energia para a prática de exercícios e não as reservas que você já possui. 
-Frutas: uma porção de banana nanica (1 unidade) equivale $d I$ unidade de laranja ou $\frac{1}{2}$ mamão papaya ou 1 fatia de melancia.

*Leguminosas: uma porção de feijão (1 concha) equivale à $1 \frac{1}{2}$ colher de sopa de grão de bico cozido ou 2 colheres de sopa de lentilha.

* Carnes e ovos: uma porção de carne (1 bife grelhado) equivale à 1 filé de frango grelhado ou 2 ovos cozidos ou 1 filé de peixe.

*Leite e derivados: uma porção de leite (1 copo de requeijão) equivale à 1 pote de iogurte ou $1 \frac{1}{2}$ fatia de queijo branco ou 3 fatias de queijo mussarela.

* Óleos e gorduras: uma porção de azeite (1 colher de sopa) equivale à 1 colher de sopa de óleo de girassol/ soja ou $\frac{1}{2}$ colher de sopa de manteiga/ margarina.

"Açúcares: uma porção de açúcar (1 colher de sopa) equivale a $\frac{1}{2}$ fatia de doce industrializado tipo goiabado ou $2 \frac{1}{2}$ colheres de sopa de mel.

\section{LEMBRE-SE DE PRATICAR ATIVIDADE FISICA REGULARMENTE PARA \\ MANTER A BOA FORMA!}

\section{ORIENTAÇÕES PARA UMA ALIMENTAÇÃO SAUDÁVEL}

Evite pular refeições, principalmente o café da manhã, é importante não permanecer longos periodos em jejum. Dê preferência ao consumo de frutas, leite e/ ou derivados e pães ou cereais matinais no café da manhã.

Procure não substituir refeições como almoço e jantar por lanches. Para compor uma refeição adequada você pode consumir arroz, feijão, salada (com hortaliças cruas e cozidas), uma porção de carne (frango, peixe, boi) e como sobremesa, uma fruta.

Entre o café da manhã, almoço e jantar, você poderá ingerir frutas, sucos, vitaminas, iogurtes e pães. Lembre-se de que, quanto maior o número de refeições mais completa $e$ saudável será sua alimentação. 
Isto não significa que você passará a comer mais, apenas estará distribuindo os alimentos de forma adequada.

Sorvetes, salgadinhos industrializados, chocolates, frituras, refrigerantes e biscoitos não são proibidos, mas devem ser consumidos esporadicamente e com moderação.

\section{IMPORTÂNCIA DO CONSUMO DE} ALGUNS GRUPOS DE ALIMENTOS DURANTE A ADOLESCENNCIA

*frutas e hortaliças: fornecem fibras, vitaminas e minerais, que são importantes para a manutenção do equilibrio do organismo. Se você quer ter uma pele bonita não pode deixar de consumir estes alimentos! *leite e derivados: contêm cálcio, mineral essencial para o bom desenvolvimento dos ossos e, portanto, para sua força física. Além disso, a ingestão de cálcio previne a osteoporose.

*carnes: ricas em ferro, que é um mineral essencial para o crescimento e prevenção de anemia. Oferece melhor disposição para a realização das atividades do dia a dia $e$ prática de atividade física.

\section{GUIA PARA UMA ALIMENTAÇÃO}

$$
\text { ADEQUADA }
$$

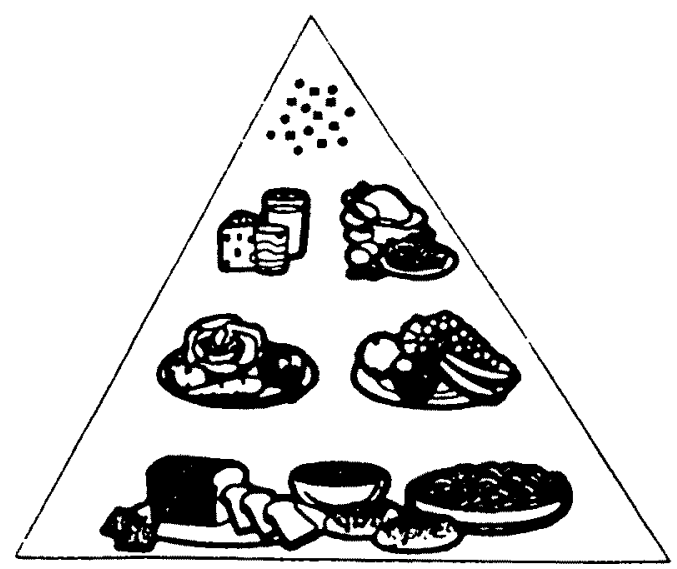

Esta pirâmide indica a melhor maneira para você compor sua alimentação. Os alimentos localizados na base devem ser consumidos em maior proporção e os pertencentes ao ápice da pirâmide precisam ser ingeridos com moderação.

\section{GUTA DE SUBSTITUIÇŐES}

*Pães, raízes e cereais: uma porção de arroz (4 colheres de sopa) equivale à 1 unidade de pão francês ou 2 fatias de pão de forma ov $3 \frac{1}{2}$ colheres de sopa de macarrão ou 2 colheres de servir de purê de batata.

* Hortaliças (verduras e legumes): uma porção de brócolis cozido (4 $\frac{1}{2}$ colheres de sopa) equivale à 1 colher de servir de cenoura crua picada ou 4 fatias de tomate ou 3 colheres de sopa de espinafre cozido. 
porções. A diferença de preço pode ser pequeno. mas de calorias não é... ou então, divida a maior porção com um amigo... esta dica também vale para pipoca, batato frita, etc.

* Beba pelo menos 2 litros de água por dia no intervalo das refeiçöes;

*Evite os queijos amarelos, maionese e creme de leite, pois eles contêm muita gordura;

*Cuidado com o uso excessivo de embutidos como: mortadela. presunto, salame, etc, consuma com moderação:
*Procure levar una vida mais ativa, evite permanecer longos periodos em frente d TV, jogando video games ou utilizando Internet. Tente andar mais de bicicleta, ou até mesmo a pé. Se possivel, nunca deixe de praticar exercicios físicos. procure algo que the dê prazer $e$ seja compativel com o seu dia a dia.

Elizabeth Maria Bismarck Nasr

Nutricionista - CRN 12853 Junho/2004

\section{ORIENTAÇÕES PARA}

MANUTENÇÃO DO PESO CORPORAL

Parabénst $O$ resultado da sua avaliação física indicou que seu peso está adequado para a sua altura. Este folheto contém algumas dicas para você continuar mantendo uma boa forma física.

*Evite consumir tudo aquilo que você já sabe que nđo é saudável: lanches em fast foods. salgadinhos, refrigerantes, frituras. chocolates, etc.

*Procure consumir 6 refeições por dia: café da manhã, lanche da manhã, almoço, lanche da tarde, jantar e lanche da noite. Mas escolha bem os alimentos, para isso consulte o folder sobre alimentação saudável. 
*Inicie suas refeições principais c: -

as saladas, além de fornecer diversas vitaminas, também contém fibras, que auxiliam no bom funcionamento do intestino. Quanto mais variada e colorida for sua alimentação, maior será a quantidade de vitaminas que você estará consumindo.

* Dê preferência para as carnes brancas, pois são mais magras. Evite muitas frituras, consuma as cornes assadas, grelhadas, refogadas ou ensopadas:

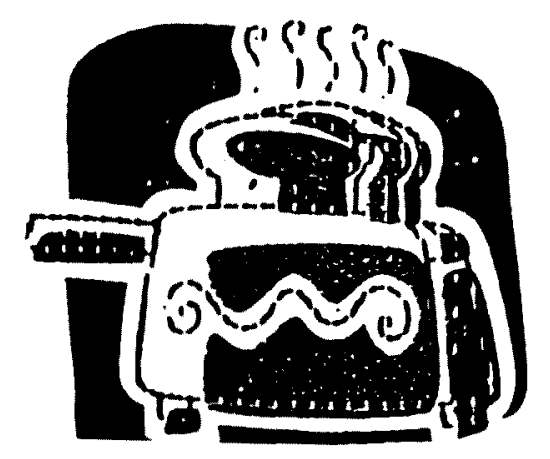

"Noo consuma liquidos durante as refeições:

"Procure ingerir maior quantidade de frutas e hortaliças cruas:

* Sanduiches podem substituir as refeições, desde que não se tornem uma substituição freqüente e sejam preparadas com alimentos saudáveis e sem muita gordura. Evite alimentos como maionese, bacon, etc. Para acompanhar o sanduiche, escolha sempre um suco de frutas:

"Pense na sua saúde quando for escolher seus lanches:

- fuja daqueles sanduiches naturais que contém muita maionese (se for preparar em casa utilize pouca maionese ou molhos a base de iogurte),

- evite comprar salgadinhos fritos ou industrializados (prefira salgados assados).

- se sentir vontade de comer um doce ou chocolate, escolha as embalogens menores.

- evite consumir refrigerantes ou sucos artificiais (prefira sucos naturais ou de preferência, consuma a própria fruta).

- se por acaso for comprar um refrigerante em lanchonetes tipo fost foods, evite as grandes 
presunto, salame, etc, consuma com moderaçăo:

* Sanduiches podem substituir as refeições. desde que não se tornem uma substituição freqüente e sejam preparadas com alimentos saudáveis e sem muita gordura. Evite alimentos como maionese, bacon, etc. Para acompanhar o sanduiche, escolha sempre um suco de frutas:

* Beba pelo menos 2 litros de água por dia no intervalo das refeições:

* Não consuma liquidos durante as refeições:

- Procure sentar-se confortavelmente à mesa na hora das refeições. Alimentese com calma, sem pressa. Mastigue muito bem os alimentos, concentre-se naquilo que come e aprecie o sabor. cheiro e a consistência dos alimentos:

* Procure manter a atmosfera alegre e feliz d hora das refeiç̋es, sem trazer os problemas do dia-a-dia para a mesa:

* Lembre-se de praticar atividade física para auxiliar na perda de peso. Escolha algo que the dê prazer: caminhadas, natação, bicicleta, etc:

* Cuidado: perdas de peso maiores de t $\mathrm{kg}$ por semana não fazem bem ao organismol!!

Elizabeth Maria Bismarck Nesr Nutricionista - CRN 12853 Junho/2004
DICAS QUE AJUDAM A PERDER PESO COM SAÚDEIII

* Para conseguir emagrecer com saúde é importante prestar muita atençao nos alimentos que você está escolhendo para comer... Aproveite estas dicas:

* Evite consumir alimentos ricos em gordura e açúcares simples, como: frituras, refrigerantes, salgadinhos, bolachas recheadas, sorvetes, sucos artificiais, milk-shakes e lanches em fast foods, etc:

* Para emagrecer não significa que você vai "passar fome", procure fazer de 5 a 6 refeições por dia: café da manhã, lanche da manhã. almoço, lanche da tarde, jantar e lanche da noite: 
* É importante respeitar os horários das refeições: procure não "pular" refeições, nem "beliscar" nos seus intervalos, pois horários regulares ajudam no bom funcionamento do organismo;

* Capriche bastante no seu café da manhã: tome leite ou iogurte (você pode bater com frutas para substituir os achocolatados, que são mais calóricos) e coma pão ou bolo simples (evite as bolachas - até mesmo as salgadas contém bastante gordura):

* Nos lanches da manhã, tarde e noite consuma frutas:

* Se sentir vontade de comer algum salgado, escolha aqueles que foram assados e não fritos. Fuja das massas folhadast
Inicie sua refeição (almoço e jantar) com saladas, assim vacê vai se sentir mais satisfeito quando for comer o restante da refeição. Mas cuidado com os temperos da salada: utilize limão, vinogre, ervas finas. Molhos à base de maionese devem ser evitados e o azeite (apesar de ser saudável) deve ser consumido com moderação, pois quando em excesso. também engorda:

* No almoço e jantar você também pode consumir arroz e feijão, mas não exagere na dose... Estes alimentos são importantes para manter a saciedade entre as refeições e fornecem energia. Às vezes a gente deixa de consumir alimentos saudáveis pensando que eles engordam (e não é verdade) e quando chega a fome, devora tudo o que encontra pela frente Geralmente doces, salgadinhos ... não é uma boa troca...);

* Dê preferência para as carnes brancas, pois são mais magras. Quando for prepará-las, retire toda gordura aparente das carnes e a pele do frango. Evite muitas frituras, consuma as carnes assadas. grelhadas, refogadas ou ensopadas:

* Procure ingerir maior quantidade de frutas e hortaliças cruas:

* Evite os queijos amarelos, maionese e creme de leite, pois eles contêm muita gordura:

* Cuidado com o uso excessivo de embutidos como: mortadela, 
ANEXO III 
UNIVERSIDADE DE SÃO PAULO

FACULDADE DE SAÚDE PÚBLICA

DEPARTAMENTO DE NUTRIÇÃO

São José dos Campos, Maio de 2004.

\section{Pesquisa: Relagio entre as condiçöes nutricionais ao nascer e composiçäo corporal de adolescentes e jovens adultos.}

Prezados pais e/ou responsáveis

Estou desenvolvendo um projeto de Mestrado com o objetivo de estudar a relação entre as condições de nutrição da criança durante o nascimento (peso, comprimento, idade gestacional, tempo de aleitamento materno) com a atual composição corporal de adolescentes.

Para tanto, será necessário realizar algumas medidas antropométricas (peso, estatura, circunferência da cintura) e um exame (bioimpedância) para verificar a \% de massa muscular e de gordura corporal nos adolescentes matriculados neste Colégio. Nesse sentido, gostaria de convidar seu filho (a) para participar desta pesquisa

As informaçð̃es referentes às condições de nascimento de seu filho (a) precisam ser obtidas em algum documento entregue pela maternidade com tais dados. Como por exemplo, o cartão sobre as condiçð̄es de nascimento da criança (documento entregue pela maternidade, com informações sobre a idade gestacional, peso ao nascer, comprimento ao nascer, entre outros, geralmente tem a impressão do pezinho da criança). Estas informações são fundamentais para a realização da pesquisa, portanto, solicito uma última gentileza, de entregar este documento para os seus filhos para que, no próprio Colégio, esta informação seja coletada.

Após realização das medidas antropométricas seu filho (a) receberá uma avaliação do seu estado nutricional e informaç̃es sobre alimentação saudável.

Agradeco antecipadamente a colaboração e me coloco à disposição para qualquer esclarecimento. 
TERMO DE CONSENTIMENTO LIVRE E ESCLARECIDO

PESQUISA: "Relação entre as condiçöes nutricionais ao mascer $e$ composição corporal de adolexcentes e jovens adultos"

(de acordo com a resolução 196 de 10/10/1996 do Conselho Nacional de Saúde)

Eu,

livremente, concordo em participar e autorizo meu (minha) filho(a), a participar da

pesquisa "Relação entre as condiçöes nutricionais ao nascer e composiçäo corporal de adolescentes." sob a responsabilidade da pesquisadora Elizabeth Maria Bismarck Nast, mestranda da Faculdade de Saúde Pública da Universidade de São Paulo, sob orientação da Prof $^{2} \operatorname{Dr}^{2}$ Ana Maria Dianezi Gambardella da mesma instituição.

Objetivo da pesquisa: verificar a relação entre as condições nutricionais ao nascer e a composição corporal durante a adolescência.

Participação: responder a um questionário e permitir que sejam realizadas medidas de peso, estatura e circunferência da cintura e exame de bioimpedância.

Riscos: Não haverá riscos para a integridade física, mental ou moral do $\operatorname{Sr(a)}$ e seu(sua) filho(a). o exame de bioimpedância é indolor e não invasivo.

Beneficios: As informaç̃es obtidas nesta pesquisa poderão ser úteis cientificamente e, também trarð̃o informaçðes sobre a saúde do $\operatorname{Sr}(a)$ e seu(sua) filho(a).

Privacidade: Os dados individualizados serão confidenciais. Os resultados coletivos serão divulgados nos meios científicos.

Contato com os pesquisadores: Terei acesso ao telefone para esclarecimento de dúvidas e reclamações.

Desistência: Poderei desistir a qualquer momento da minha participação e de meu (minha) filho(a), sem qualquer consequêencia para mim e para ele(a).

Por favor, informe se seu filho (a) foi amamentado: ( ) sim ( ) não

Se sim, até qual idade ele (a) recebeu leite materno? meses.

Introdução da papa salgada: meses.

São José dos Campos, de de 2004, 
ANEXO IV 


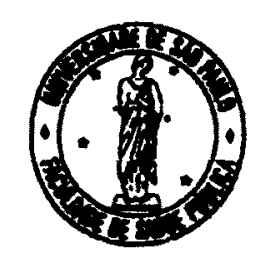

\section{Universidade de São Paulo}

Faculdade de Saúde Pública

COMITE DE ÉTICA - COEP

Av. Dr. Arnaido, 715 - CEP 01246-904 - São Paulo - Brasil

Telefones: (55-11) 3066-7779 - fone/fax (55-11) 3064-7314-e-mail: mdgracas@usp.br

\section{Of.COEP/221/03}

10 de dezembro de 2003

Pelo presente, informo que o Comitê de Ética em Pesquisa da Faculdade de Saúde Pública da Universidade de São Paulo-COEP, analisou e aprovou, em sua $10^{2} / 03$, realizada em 09.12 .03 , de acordo com os requisitos da Resolução CNS/196/96, o Protocolo de Pesquisa n." 1043, intitulado: "EFEITOS TARDIOS DO BAIXO PESO AO NASCER: EXCESSO DE PESO CORPORAL NA ADOLESCÊNCIA", apresentado pela pesquisadora Elizabeth Maria Bismarck Nasr.

Atenciosamente,

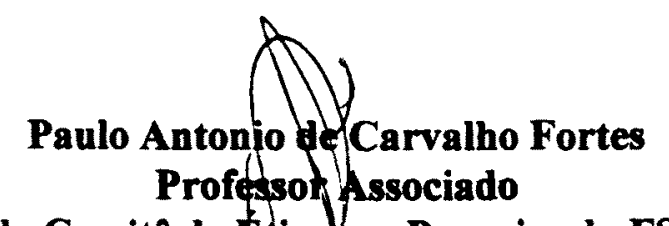

Coordenador do Comitê de ticalem Pesquisa da FSP-COEP 
ANEXO V 
UNIVERSIDADE DE SÃO PAULO

FACULDADE DE SAÚDE PÚBLICA

DEPARTAMENTO DE NUTRIÇÃO

São José dos Campos, de de 2004 .

Ao Sr. (a)

Coordenador da Instituição

Após contato prévio, formalizamos pedido de autorização para realização da pesquisa: "Relação entre peso ao nascer e excesso de peso corporal em adolescentes", sob nossa responsabilidade.

Será realizada uma pesquisa com os alunos desta instituição, com o objetivo de analisar o crescimento e composição corporal de adolescentes. Todos os alunos estarão cientes dos objetivos e metodologia do estudo e seus pais firmarão concordância com a participação na pesquisa

Enviamos cópia do projeto com detalhamento das atividades a serem realizadas e nos colocamos à disposição para eventuais dúvidas e sugestðes pelo endereço e telefone:

* Elizabeth Maria Bismarck Nasr tel.: (12) $3916-4203$

* Prof Dr $^{2}$ Ana Maria Dianezi Gambardella

Departamento de Nutrição - Faculdade de Saúde Pública - Universidade de São Paulo

Av. Dr Amaldo, 715 - CEP 01246-904 -São Paulo

Fone: (11) 3066-7705

Agradeço, novamente, a colaboração

Elizabeth Maria Bismarck Nasr 